Florida International University FIU Digital Commons

$7-25-2014$

\title{
The Effects of Paternal and Maternal Nurturance and Involvement on Young Adult Academic Outcomes
}

Tara Sheehan

Florida International University, tarashee@nova.edu

DOI: $10.25148 /$ etd.FI14071165

Follow this and additional works at: https://digitalcommons.fiu.edu/etd

\section{Recommended Citation}

Sheehan, Tara, "The Effects of Paternal and Maternal Nurturance and Involvement on Young Adult Academic Outcomes" (2014). FIU Electronic Theses and Dissertations. 1506.

https://digitalcommons.fiu.edu/etd/1506 


\section{FLORIDA INTERNATIONAL UNIVERSITY}

Miami, Florida

THE EFFECTS OF PATERNAL AND MATERNAL NURTURANCE AND INVOLVEMENT ON

YOUNG ADULT ACADEMIC OUTCOMES

A dissertation submitted in partial fulfillment of the

requirements for the degree of

DOCTOR OF PHILOSOPHY

in

PSYCHOLOGY

by

Tara Sheehan

2014 
To: Interim Dean, Michael R. Heithaus

College of Arts and Sciences

This dissertation, written by Tara Sheehan, and entitled The Effects of Paternal and Maternal Nurturance and Involvement on Young Adult Academic Outcomes, having been approved in respect to style and intellectual content, is referred to you for judgment.

We have read this dissertation and recommend that it be approved.

$\begin{array}{r}\hline \text { Gordon Finley } \\ \hline \text { Robert Lickliter } \\ \hline \text { Barbara Thomlison } \\ \hline \text { Seth Schwartz } \\ \hline \text { Mary Levitt, Major Professor }\end{array}$

Date of Defense: June 25, 2014

The dissertation of Tara Sheehan is approved.

Interim Dean Michael R. Heithaus College of Arts and Sciences

Dean Lakshmi N. Reddi University Graduate School

Florida International University, 2014 
(C) Copyright 2014 by Tara Sheehan

All rights reserved. 


\section{DEDICATION}

I dedicate this dissertation to my parents. Without their unwavering support and love, the completion of this work would not have been possible. 


\section{ACKNOWLEDGMENTS}

I wish to thank my committee for their patience, understanding, and encouragement throughout this dissertation process. I would like to give a special thank you to my mentor and advisor in this project, Dr. Gordon Finley. Dr. Finley is an expert and pioneer in this area and developed the questionnaire utilized in the project and actively and greatly contributes to basic science, public opinion, and policy change advocating for paternal rights. His mentorship and guidance in this project was crucial for my success. Thank you to Dr. Mary Levitt for your continued guidance as my major professor. Thank you to Dr. Robert Lickliter for your assistance at every step in this process and for encouraging me to complete this journey. Thank you to Dr. Seth Schwartz for your guidance in conducting the statistical analyses of this dissertation. Thank you to Dr. Barabara Thomlison for offering your expertise from outside the psychology field to enrich this project. Thank you to Dr. Dionne Stephens for offering your support and expertise.

I would also like to thank Dr. Jacob Gewirtz for his guidance throughout my graduate career. It was his passion as a developmental behavior analyst that led me to pursue a doctorate in developmental psychology. 


\section{ABSTRACT OF THE DISSERTATION \\ THE EFFECTS OF PATERNAL AND MATERNAL NURTURANCE AND INVOLVEMENT ON \\ YOUNG ADULT ACADEMIC OUTCOMES \\ by}

Tara Sheehan

Florida International University, 2014

Miami, FL

Professor Mary Levitt, Major Professor

The present study examines how mothering and fathering impact child academic outcomes in divorced and intact families, and if there are unique influences of mothering and fathering variables for sons and daughters. An ethnically diverse sample of 1,714 university students from Florida International University (n=1371) and Florida State University ( $\mathrm{n}=343$ ) responded to measures on a questionnaire that included the Nurturant Fathering and Mothering Scales (Finley \& Schwartz, 2004; Schwartz \& Finley, 2005; Finley \& Schwartz, 2006), the Mother and Father Involvement Scales (Finley, Mira, \& Schwartz, 2008), demographic measures, and academic outcome measures. In intact families, mothering and fathering variables were significantly correlated with each other, and positively correlated with child academic outcomes including grades, GPA, academic satisfaction, and academic importance. In divorced families, mothering and fathering variables were not correlated with each other. Furthermore, when analyzing divorced families, significant effects were found for both parent and child gender. Mothering variables were found to have the greatest positive impact for sons' academic outcomes. 
Maternal nurturance and maternal involvement were correlated positively with academic outcomes for sons from divorced families and accounted for $3-4 \%$ of the unique variance explained. Consistently, desired mother involvement, how much involvement the child wished they had received, was negatively correlated with academic outcomes for sons from divorced families and accounted for $10-15 \%$ of the unique variance explained. This means that when the amount of maternal involvement that sons in divorced families received matched or exceeded their desired level of involvement, sons had more positive academic outcomes including grades, GPA, satisfaction with academics and academic importance. This suggests that in intact family forms, nurturant and involved mothering and fathering have a positive effect on academic outcomes for sons and daughters. In divorced family forms, the effects of fathering on child academic outcomes were not significant. Therefore, in divorced families, the positive effects fathering on academic outcomes of sons and daughters drop out, and mothers are uniquely important for sons' academic success. 


\section{TABLE OF CONTENTS}

CHAPTER

PAGE

1. STATEMENT OF THE PROBLEM

2. LITERATURE REVIEW

4

Parental Nurturance

4

$\begin{array}{ll}\text { Cross-Cultural Research on Parental Nurturance } & 7\end{array}$

Unique Contributions of Mother and Father Nurturance 8

Measuring Parental Nurturance $\quad 9$

Parental Involvement 10

Unique Contributions of Mother and Father Involvement 10

Cross-Cultural Research on Parental Involvement 11

Measuring Parental Involvement 11

Measuring Desired Parental Involvement 16

Parenting Behaviors, Divorce and Academic Outcomes 17

$\begin{array}{lr}\text { Theoretical Perspective } & 18\end{array}$

3. RESEARCH QUESTIONS AND HYPOTHESIS 21

Parental Nurturance $\quad 21$

$\begin{array}{ll}\text { Parental Involvement } & 22\end{array}$

4. METHODS 24

Sample $\quad 24$

Procedure $\quad 24$

Measures $\quad 25$

Demographics $\quad 25$

Nurturant Fathering and Mothering Scales $\quad 25$

Mother and Father Involvement Scales 26

Academic Outcomes 28

5. RESULTS 29

Maternal Nurturance and Paternal Nurturance and Academic Outcomes 29

Maternal Involvement and Paternal Involvement and Academic

Outcomes 36

Effect Sizes for Nurturance, Reported Involvement, and Desired $\begin{array}{ll}\text { Involvement } & 48\end{array}$

Unique Variance Explained Analyses $\quad 49$ 
6. DISCUSSION 52

Parental Nurturance $\quad 53$

Reported Parental Involvement $\quad 54$

Desired Parental Involvement $\quad 55$

Limitations and Future Directions $\quad 56$

$\begin{array}{ll}\text { General Conclusions } & 57\end{array}$

REFERENCES $\quad 59$

$\begin{array}{ll}\text { APPENDIX } & 69\end{array}$

$\begin{array}{ll}\text { VITA } & 78\end{array}$ 
1. Parental Nurturance Effects on Child Academic Outcomes in Literature

2. Reported Maternal and Paternal Involvement Domains

3. Desired Maternal and Paternal Involvement Domains

4. Research Questions and Hypotheses

5. Nurturant Fathering Scale

6. Academic Outcome Variables

7. Correlations of Maternal and Paternal Nurturance by Family Form

8. Correlations of Maternal Nurturance and Paternal Nurturance with Academic Outcomes

9. Correlations of Maternal Nurturance and Paternal Nurturance with Academic Outcomes by Child Gender

10. Correlations of Maternal Nurturance and Paternal Nurturance with Academic Outcomes by Family Form

11. Mother Nurturance and Father Nurturance Correlations with Academic Outcomes for Sons from Intact Families

12. Mother Nurturance and Father Nurturance Correlations with Academic Outcomes for Daughters from Intact Families

13. Mother Nurturance and Father Nurturance Correlations with Academic Outcomes for Sons from Divorced Families

14. Mother Nurturance and Father Nurturance Correlations with Academic Outcomes for Daughters from Divorced Families

15. Correlations of Reported Maternal and Paternal Involvement by Family Form

16. Correlations of Desired Maternal and Paternal Involvement by Family Form 
17. Correlations of Reported Maternal and Paternal Involvement with Academic Outcomes

18. Correlations of Desired Maternal and Paternal Involvement with Academic Outcomes

19. Correlations of Reported Maternal and Paternal Involvement with Academic Outcomes by Child Gender

20. Correlations of Desired Maternal and Paternal Involvement with Academic Outcomes by Child Gender

21. Correlations of Reported Maternal and Paternal Involvement with Academic Outcomes by Family Form

22. Correlations of Desired Maternal and Paternal Involvement with Academic Outcomes by Family Form

23. Impact of Mothering on Sons from Divorced Families

24. Impact of Mothering on Sons from Intact Families

25. Impact of Mothering on Daughters from Divorced Families

26. Impact of Mothering on Daughters from Intact Families

27. Impact of Fathering on Sons from Divorced Families

28. Impact of Fathering on Sons from Intact Families

29. Impact of Fathering on Daughters from Divorced Families

30. Impact of Fathering on Daughters from Intact Families

31. Rank Order of Effect Sizes for Mother and Father Nurturance, Reported Involvement and Desired Involvement

32. Unique Variance Explained Analyses 


\section{CHAPTER 1}

\section{STATEMENT OF THE PROBLEM}

According to the U.S. Census Bureau (2002), the national divorce rate is 43\%. Research has demonstrated that being a child from a divorced family is correlated with negative outcomes across a variety of domains including psychological problems (Zill, Morrison, \& Coiro, 1993), problem externalizing behaviors (Martinez, Marion, \& Forgatch, 2002), and academic outcomes (Barber, 1998; Bertram, 2006 \& Jeynes, 2002). With nearly half of all marriages ending in divorce, it becomes increasingly important to examine family processes in the context of divorce.

A common result of the divorce process is that one parent leaves the primary residence and becomes a non-resident parent. Non-resident parents spend less time with children and therefore parenting process between non-resident parents and their children are affected (Heard 2007). In most cases, it is the father who adopts the role of a nonresident parent (Popenoe, 1996; Pruett, Cowen, Cowen, \& Diamond, 2012). The role of fathering variables in child rearing must be examined as evolving societal conditions of divorce threaten the frequency and magnitude of fathers' influence on child development, with potentially detrimental results. A reduction in fathering and absent fatherhood has complex influence on the family system, often negatively impacting mothers, children, and fathers. Recent researcher have been calling for more research on fathering processes (Coltraine \& Behnke, 2013; Hofferth, Pleck, Goldscheider, Curtin, \& Hrapcynski, 2013; Scott, Peterson, Ikramullah, \& Manlove, 2013).

According to a Family Systems Theory perspective, relationships among family members influence developmental outcomes for each family member. The family is the 
most critical system affecting child development, especially parent-child relationships. Nurturant and involved mothering and fathering shape an environment within a family system that affords opportunities for positive child development. When both biological parents are able and willing to be available to their child, then every effort should be made to provide children with meaningful relationships with both parents. The recent increased prevalence of court awarded joint child custody is consistent with this sentiment. It is important for public policies and legal proceedings to be informed by research on family process and "best interests of the child" that is current with societal trends including divorce and alternative family structures to the traditional nuclear family including non-martial childrearing and remarriage (Krampe \& Newton, 2012; Schwartz \& Finley, 2010) Unfortunately, intersection between research and policy has not always been timely (Cabrera, 2010).

The purpose of this research study is to examine two important dimensions of parenting: nurturance and involvement, and the impact that these parenting behaviors have on adult children's academic outcomes. Because child academic performance dictates many opportunities, conditions, and quality of life, it is a crucial outcome measure that calls for further scientific inquiry.

This research study is an extension of the work done by Finley and colleagues (Finley \& Schwartz, 2004, 2007, 2010; Finley, Mira, \& Schwartz, 2008; Mira, 2006; Schwartz \& Finley, 2005, 2009; Williams \& Finley, 1997) on parental nurturance and involvement. The work of Finley and colleagues has yielded socially valuable findings and the creation of new scales to measure constructs integral to family relations and child development, from a phenomenological perspective where young adult children retrospectively report 
on their perceived experience of mothering and fathering. This study examines the impact of paternal and maternal nurturance and involvement on child academic outcomes, including grades, GPA, expected academic performance and satisfaction with academic performance, for young adult college students. With divorce and child custody currently being such important topics in society, the study examines variables of interest to the academic community, to policy makers, and to the general public. 


\section{CHAPTER 2}

\section{LITERATURE REVIEW}

The review includes a consideration of the literature pertaining to previous research on the role of parental nurturance and involvement with respect to children's academic outcomes. Research on parental nurturance is reviewed first, followed by literature on parental involvement. The unique contributions of mothers and fathers, cross cultural findings, and measurement issues are addressed throughout the review. Well-documented global effects of divorce on children's academic outcomes are reviewed briefly. Finally, the theoretical basis for the research is detailed.

\section{Parental Nurturance}

An extensive literature shows that parenting behavior is a major predictor of child outcomes. An important dimension of parenting behavior is nurturance, an affective domain of parenting (Hunter, 2003; Rohner \& Veneziano 2001; Sands \& Plunkett, 2005; Schwartz \& Finley 2010). The parental nurturance construct has been studied under a variety of descriptors including warmth, love, supportiveness, acceptance, closeness, caring, and affection (Beyer, 1995; Landsford et al., 2006; Rollande, 2000; Wagner \& Phillips, 1992; Vazsyoni 2003). Regardless of which label is used for the construct, parental nurturance has been strongly linked to a host of child outcomes, including those in the cognitive/intellectual/academic domain (Beyer, 1995; Jenkins 2013, Melby \& Conger 1996; Parmar \& Rhoner, 2004; Sands \& Plunkett 2005).

Parenting, when it provides high levels of nurturance and emotional support, has been correlated with the development of instrumental competence and cognitive abilities in children (Bahal \& Sexena, 1978; Chen, Rubin \& Li, 1997; Jeneys, 2003) and 
educational aspirations in adolescents (Marjoribanks, 1997). Nurturant and involved parenting has been demonstrated to directly affect adolescent academic performance in a positive direction (Glasgow, Dornbusch, Troyer, Steinberg \& Ritter, 1997; Kim 1999; Lakshmi \& Arora, 2006; Melby \& Conger, 1996; Steinberg, Lamborn, Bornbusch \& Darling, 1992). Parental nurturance was found to be uniquely predictive of obtaining career goals in young adults (Hunter, 2003). When parenting provides low levels of nurturance, it has been correlated with negative child academic outcomes (Casaonva, Garcia-Linones, Manuel \& Carpio, 2005; Taylor, Hinton, \& Wilson, 1995). In a research study in which the participants were assigned into two groups, academic failures and academic successes (based on adolescent responses to an interview) the failure group’s home environments were found to have little positive interaction, deficient nurturance and a lack of educational opportunities (Finn, 1979). Table 1 summarizes the consistent findings in the literature of the positive effects of parental nurturance on child academic outcomes across child age, nurturance variable, ethnicity, who reports, and the parent that is rated. As depicted in Table 1, a positive relationship between parental nurturance and child academic outcomes is robust in that consistent findings are demonstrated across child age, variable measured, child ethnicity, types of reporters (parents, teachers, and/or children), and whether the parent rated was mother or father (Dornbusch et. al. 1987, Grey \& Steinberg 1999, Lansford et. al. 2006, \& Vazsonyi, 2003). The positive relationship between parental nurtance and child academic outcomes has been consistently demonstrated in both concurrent and longitudinal studies (Beyer, 1995). 


\begin{tabular}{|c|c|c|c|c|c|c|}
\hline \multicolumn{7}{|c|}{ Parental Nurturance Effects on Child Academic Outcomes in Literature } \\
\hline Study & Age & $\begin{array}{l}\text { Nurturance } \\
\text { Variable }\end{array}$ & Direction & Ethnicity & $\begin{array}{c}\text { Who } \\
\text { Reports }\end{array}$ & $\begin{array}{l}\text { Parent } \\
\text { Rated }\end{array}$ \\
\hline Lansford et al. (2006) & EC-EA & Support & positive & C & $P, C, S R$ & $P$ \\
\hline $\begin{array}{c}\text { Adams \& Ryan } \\
\text { (2005) }\end{array}$ & C-EA & $\begin{array}{l}\text { Support } \\
\text { Warmth }\end{array}$ & positive & C & $\mathrm{C}, \mathrm{T}$ & $M \& F$ \\
\hline $\begin{array}{l}\text { Vazsonyi } \\
\text { (2003) }\end{array}$ & A & Support & positive & C & C & $M \& F$ \\
\hline $\begin{array}{l}\text { Rollande } \\
(2000)\end{array}$ & A & Warmth & positive & C & C & $\mathrm{P}$ \\
\hline $\begin{array}{c}\text { Gray \& Steinberg } \\
\text { (1999) }\end{array}$ & A & Acceptance & positive & $\begin{array}{c}C, A, H, B \\
O\end{array}$ & C & $\mathrm{P}$ \\
\hline Scarmella et al. (1998) & EA-A & Warmth & positive & $\mathrm{C}$ & $C, P, T$ & $M \& F$ \\
\hline $\begin{array}{l}\text { Coley } \\
(1998)\end{array}$ & EC-C & Warmth & positive & $\mathrm{C}, \mathrm{B}$ & C & $M \& F$ \\
\hline $\begin{array}{l}\text { Pettit et al. } \\
\text { (1997) }\end{array}$ & EC-C & $\begin{array}{c}\text { Warmth } \\
\text { Support } \\
\text { Acceptance }\end{array}$ & positive & $C, B, O$ & $C, P$ & $M$ \\
\hline $\begin{array}{c}\text { Beyer (lit review) } \\
\text { (1995) }\end{array}$ & EC-A & Warmth & positive & multi & multi & $M$ \\
\hline $\begin{array}{c}\text { DuBois et al. } \\
\text { (1994) }\end{array}$ & C-EA & Acceptance & positive & $\mathrm{B}, \mathrm{C}$ & $\mathrm{C}, \mathrm{SR}$ & $\begin{array}{c}\text { Resident } \\
\text { Parent }\end{array}$ \\
\hline $\begin{array}{l}\text { Mazur } \\
(1993)\end{array}$ & EA & $\begin{array}{l}\text { Acceptance } \\
\text { Support }\end{array}$ & positive & $C, H, B$ & $C, P$ & $M$ \\
\hline $\begin{array}{c}\text { Wagner \& Phillips } \\
\text { (1992) }\end{array}$ & C & Warmth & positive & C & C, DO & $M \& F$ \\
\hline $\begin{array}{c}\text { Steinberg et al. } \\
\text { (1989) }\end{array}$ & EA-A & Acceptance & positive & $\mathrm{C}$ & $C, S R$ & $M \& F$ \\
\hline $\begin{array}{c}\text { Dornbusch et al. } \\
\text { (1987) }\end{array}$ & A & Warmth & positive & $C, A, H, B$ & $C, S R$ & $P$ \\
\hline $\begin{array}{c}\text { Estrada et al. } \\
(1987)\end{array}$ & EC-EA & $\begin{array}{c}\text { Warmth } \\
\text { Acceptance }\end{array}$ & positive & C & $C, P$ & $M$ \\
\hline $\begin{array}{c}\text { Ranschburg \& Bolla } \\
\text { (1985) }\end{array}$ & A & Warmth & positive & C & & \\
\hline
\end{tabular}

Note: Table 1 lists the study by author and year, the age of the children in the study (Age key: EC =Early Childhood, $\mathrm{C}=$ Childhood, EA=Early Adolescence, $\mathrm{A}=$ Adolescence), the nurturance variable used, the direction of effects between parental nurturance and child academic outcomes, ethnicity of participants ( $\mathrm{C}=$ Caucasian, $\mathrm{A}=\mathrm{A}$ sian, $\mathrm{H}=\mathrm{Hispanic}$, $\mathrm{B}=\mathrm{Black}, \mathrm{O}=\mathrm{Other})$, and who reported on the nurturance and academic outcomes $(\mathrm{P}=$ parent rated, $\mathrm{C}=$ child rated, $\mathrm{SR}=$ school records, $\mathrm{T}=$ teacher rated, $\mathrm{DO}=$ direct observation), and parent rated is which parent(s) nurturance measures were recorded for $(\mathrm{M}=$ mother, $\mathrm{F}=$ father, $\mathrm{P}=$ parent- study used term parent and did not specify).

Although the fact that parental nurturance affects child academic outcomes is clear, how that impact manifests itself is quite complex. Findings demonstrate differential effects among dimensions of parenting on single and multiple child outcomes. Added complexity is revealed through research results that suggest that the effect of parental nurturance may be moderated by child developmental level (Strange \& Brandt, 
1998). Similarly, developmental level and current developmental tasks being navigated by the parent significantly impact nurturant parenting behavior (Scaramella, Conger, Simons \& Whitbeck, 1998). Because developmental accounts of parenting are often complex, they prove to be methodologically challenging. Data collected at different developmental stages may produce discrepancies regarding variables and processes for each member of the family system. As participants are instructed to provide responses based on experiences across developmental levels and tasks, retrospective measures, like the one used in the present study, may prove less resistant to developmental artifacts and more predictive of actual experience (Finley \& Schwartz, 2010).

Cross-Cultural Research on Parental Nurturance. The nurturance construct seems to be universal and robust, with heterogeneous responses to nurturant parenting behavior occurring across different ethnic groups and cultures, both in the United Sates and internationally (Khaleque \& Rohner, 2002; Rohner, 1986; Rohner \& Brittner, 2002; Rohner, Khaleque, \& Cournoyer, 2005; Rohner \& Veneziano, 2001). For example, a recent study found that among Latino sub-groups (Puerto Ricans, Mexican Americans, and El Salvadorans), parenting variables of nurturance and consistency were found to vary, yet the consistent finding of higher academic achievement scores were obtained from children whose parents' behaviors demonstrated a domain of nurturant parenting and responsiveness (Jeynes 2003, 2007). Another cross-cultural study, including students from Hong Kong, Taiwan, Japan, Germany, Canada, the United States and Australia found that high school performance was dependent upon parental nurturance above any other family characteristic (Scott \& Scott, 1989). A study with a sample of participants from Hungary, the Netherlands, Switzerland, and the United States found 
that for all groups, maternal nurturance was negatively correlated with a variety of deviant outcomes, including school misconduct (Vazsonyi, 2003). Overall, the literature indicates that nurturant parenting is associated with a variety of positive outcomes for children of all ages, from diverse cultural backgrounds (Khaleque \& Rhoner, 2002; Rohner \& Britner, 2002; Rohner, Khaleque, \& Cournoyer 2005; Rohner \& Veneziano, 2001; and Veneziano 2003).

Unique Contributions of Mother and Father Nurturance. Adding additional complexity to the relation between parental nurturance and child outcomes is evidence that mother nurturance and father nurturance may have separate, unique effects on outcome variables. Recently, researchers have been utilizing hierarchical regression analyses and structural equation modeling techniques to identify unique variance accounted for by maternal and paternal nurturance on outcome variables. For some outcome variables, maternal nurturance has demonstrated stronger effects than paternal nurturance, whereas paternal nurturance has been found to produce stronger effects in other child outcomes (Rohner \& Veneziano, 2001). For example, it was found that maternal support (a construct similar to nurturance), but not paternal support, was positively related to academic competence as reported by their adolescent offspring (Scaramella, Conger, Simons \& Whitbeck, 1998). Conversely, a recent literature review highlighted findings demonstrating that paternal nurturance is uniquely positively associated with the intellectual development of children (Amato, 1994). More investigation is required in the field to address the issue of the unique and relative contributions of maternal and paternal nurturance to child outcome variables including 
academic outcomes to answer the question if mothering or fathering are uniquely important for child academic achievement.

Measuring Parental Nurturance. Even though the construct of nurturance has been examined extensively in the literature, there has been little agreement on how to measure nurturance since it is a complex and multiply influenced parent-child developmental process (Holden, 1990; Holden \& Edwards, 1989; and Locke \& Prinz 2002). A variety of measurement approaches have been utilized to assess parental nurturance, including behavioral observations (Landsford et al., 2006; Wagner \& Phillips, 1992), interviews (Dornbusch et al., 1987), and questionnaires (Beyer, 1995). These approaches have been employed from the parental perspective, child perspective, and teacher perspective, or any combination of these.

Measures of nurturance have been developed and implemented from different theoretical approaches with differing psychometric properties. The present study approaches the problem area from a phenomenologically-based theoretical perspective, using a retrospective measure taken from reports on perceived parenting behavior from participating young-adult children.

Specifically, the present study employed the Nurturant Fathering Scale, as well as the Nurturant Mothering Scale, both developed by Finley and colleagues, to measure both father and mother nurturance (Williams \& Finley, 1997; Finley \& Schwartz, 2004; Schwartz \& Finley, 2005; Finley \& Schwartz, 2006; and Mira, 2006). These Nurturant Parenting Scales are suitable for the measurement needs of the current project because these scales can be used for both divorced and intact family forms. Rohner's widely used and cited Parental Acceptance-Rejection Questionnaire (PARQ), which was designed to 
measure the warmth dimension of parenting, correlates highly - at .80 - with the Nurturant Fathering and Nurturant Mothering Scales in the proposed study, thus providing validation that the Nurturant Fathering and Nurturant Mothering Scales are in fact measuring the intended construct (Williams \& Finley, 1997). Also, because the related PARQ measure has been demonstrated to be useful in cross-cultural studies, the Nurturant Parenting Scales are suitable for the current project, which draws upon a culturally diverse population with a high percentage of newly emigrated South Floridians. The Nurturant Parenting Scales offer the advantage over the PARQ because it collects data and allows for analyses across family form, parent gender, and child gender. Parental Involvement

An additional important dimension of parenting behavior is involvement. Some researchers include a measure of nurturance as a domain within involvement (Fan \& Chen, 2001). Other researchers have included involvement within nurturance measures, such as acceptance (Gray and Steinberg, 1999) and supportive parenting (Pettit, Bates \& Dodge, 1997). Measures of nurturance and involvement correlate highly, but should remain conceptually distinct because evidence suggests unique contributions of nurturance and involvement on child outcomes. For example, recent meta-analyses have demonstrated that paternal warmth, but not paternal involvement, was linked to psychosocial functioning in both divorced (Amato \& Gilbreth, 1999) and intact family forms (Venziano, 1998, 2003).

Unique Contributions of Mother and Father Involvement. There is a growing body of research documenting the unique contributions of mother involvement and father involvement and the necessity of taking the difference into methodological consideration 
(Amato \& Gilbreth, 1999; Bronte-Tinkew, Moore, Capps \& Zaff 2004; \& Williams \& Kelly 2005). For example, father involvement was found to make a unique contribution to the adolescent offspring's current GPA in the affective domain of paternal involvement (Palmer, 2004). In another study, mother and father involvement were found to have differential effects when gender of child was examined. Mother involvement was found to impact (through a mediational relationship with motivation) daughters' academic achievement, whereas father involvement was found to have the same relationship for sons only (Trama, 2002).

Given empirical evidence for unique maternal and paternal contributions to child development, researchers would be advised to use caution when utilizing mean comparisons to examine mother and father involvement. Also, as evidence suggests that maternal and paternal involvement have differential effects on sons and daughters, it is important to examine moderating effects of child gender when examining the influence of parental involvement on child outcomes (Finley \& Schwartz, 2007; Nielson, 1999).

Cross-Cultural Research on Parental Involvement. Like nurturance, the literature suggests that parental involvement may be a universally important domain of parenting, affecting child outcome variables across cultures within the United States. Empirical support for parental involvement affecting child outcomes has been found for Caucasian Americans (Simpkins, 2006), African Americans (Taylor, Hinton \& Wilson, 1995), Asian Americans (Mau, 1997), and Hispanic Americans (Jeynes, 2003, 2007).

Measuring Parental Involvement. The term involvement is quite general and does not lend itself easily to operationalization. Thus, it not surprising that researchers have differentially approached the construct in the literature. The literature on the impact 
of parental involvement on child academic outcomes has yielded mixed results, and these mixed findings are likely a result of variation in conceptualizations and operational definitions of parental involvement (Hong \& Ho, 2005). When studying child academic performance, researchers have typically examined specific school involvement behaviors, including parental attendance at school functions, reading to children, monitoring homework (Jeynes, 2003) and more general, often time-based, measures of involvement (Hawkins \& Palkovitz, 1999).

Using time-based measures to study effects of parental involvement is problematic, because time-dependent measures do not account for quality of involvement or for domains of involvement that do not necessarily involve one-on-one time with the child. Time-dependent measures of parental involvement, which have been traditionally adopted in the literature, are particularly flawed when assessing paternal involvement, as mothers typically assume the direct caregiving role characterized by high rates of interacting with children. Operationalizing paternal involvement as direct interaction with children makes it a discrete, measurable event with a discernable beginning and end. Defining paternal involvement as an observable phenomenon of time spent actively engaged in parenting behavior with children has the advantage of being easily measured, quantified and analyzed, thereby lending itself to a variety of research designs and providing a multitude of research opportunities.

Unfortunately, conceptualizing paternal behavior in terms of direct interaction limits the scope of research to only a small percentage of father involvement (Hawkins \& Palkovitz, 1999). Paternal involvement is often indirect and covert, and occurs in spheres of influence outside direct father-child interactions, at the behavior-environment level of 
analysis (Amato, 1998; Finley \& Schwartz, 2006). It is problematic for society to set criteria of good fathering as providing income and being responsible for child welfare, and then define nurturant fathering in terms of time spent in direct caregiving roles. It is societal conditions that shape change in spheres of paternal involvement. "Secular change is complex and clearly does not affect all individuals equally or all behavior patterns to the same extent. In fact, it is a serious oversimplification to assume that general societal trends can isomorphically be applied across all individual fathers and families... better guidelines are necessary to illuminate which aspects of processes within families are most likely to be altered by historical events and which processes are less amenable to change" (Parke, 2002, p 60). What is clear is that the changing American cultural landscape threatens paternal involvement for future generations as social policy and legal practices remove fathers from the integral role that they have always played in the family system. The present call for protecting paternal involvement is not motivated by a religious agenda or family moralist standpoint, but rather by scientific evidence that positive developmental outcomes result for all members of the family system, and society at large, through positive father-child relationships.

Recognizing the limitations of restricting paternal involvement to temporal measures, Lamb (1986) introduced a broader conceptualization to the father literature that involves three types of involvement: interaction, accessibility and responsibility. Interaction is defined as time spent directly interacting with children, the traditional conceptualization of paternal involvement. Paternal accessibility is time that a father is available to the child, even if not directly interacting with the child. Accessibility involves willingness to parent based on child need and mental energy devoted to the 
parental role. Responsibility is the degree to which fathers protect the child's welfare involving breadwinning, mentoring, guiding and monitoring.

It is especially important to include the domain of responsibility in the definition of paternal involvement, because these types of parenting behaviors are shaped and reinforced in fathers by society. It is erroneous to operationalize paternal involvement as caretaking behavior in a social context that causes fathers to spend vast amounts of time away from home, breadwinning, as well as devoting mental resources planning for the welfare of children. A conceptualization of paternal involvement, that does not account for all of the emotional, physical and temporal resources allocated by fathers to the responsibility for the welfare of children, will grossly underestimate levels of paternal involvement and the importance of that involvement to the development of both father and child (Amato, 1994; Barnett \& Wilson, 2004).

In the present study we used general measures of paternal and maternal involvement, differentiated into important domains identified by Hawkins \& Palkovitz (1999), Finley \& Schwartz (2004), and Finley, Mira, \& Schwartz (2008) through exploratory and confirmatory factor analyses. Participants rated, on 5 point scales, how involved each parent was in aspects of their lives and development, with scale points of 5 (always involved), 4 (often involved), 3 (sometimes involved), 2 (rarely involved), and 1 (never involved). The best model fits for the data were a 3-factor solution for maternal involvement and a three-factor solution for paternal involvement. The factor structures for maternal and paternal involvement were isomorphic. The factors yielded were an instrumental dimension, an expressive dimension and a mentoring/advising dimension for both mothers and fathers. The distinction of an expressive and instrumental dimension of 
parenting is consistent with the theoretical framework first outlined by Parsons and Bales (1955); the mentoring/advising dimension consisted of items from instrumental and expressive dimensions that yielded a distinct domain of parenting (Finely, Mira, \& Schwartz, 2008). Because the factor structures for mothers and fathers were identical, this measurement tool allows for direct comparisons between maternal and paternal involvement and the unique impact that mothering and fathering have on children. The items that loaded on each of the involvement dimensions are represented in Table 2 below.

Table 2

\begin{tabular}{ccc}
\hline \multicolumn{2}{c}{ Reported Maternal and Paternal Involvement Domains } & \\
\hline Instrumental & Expressive & Mentoring/Advising \\
Developing responsibility & Companionship & Mentoring \\
Ethical/moral development & Caregiving & Developing competence \\
Career development & Sharing activities/interests & Advising \\
Developing Independence & Emotional development & Intellectual development \\
Being protective & Social development & \\
School/homework & Leisure/fun/play & \\
Discipline & Physical development & \\
Providing Income & Spiritual development & \\
\hline
\end{tabular}

There is growing evidence for the methodological value of exploring different domains of involved parenting, rather than combining them to form parenting styles (Bean et. al., 2003; Henry, Plunkett \& Sands, 2011; Ross \& McDuff 2008). Information can be lost and significant effects can be masked when distinct involvement domains are collapsed into parenting styles. The present study represents an effort to identify effects 
of specific parenting domains and identify if domains within and across parents have unique predictive power and influence on academic outcomes of sons and daughters from intact and divorced family forms.

Measuring Desired Parental Involvement. In addition to measuring retrospective reports of parental involvement, the scales also measured retrospective reports of desired parental involvement. Participants compared the level of involvement they received from their mother and father in each domain to what they wanted the level of involvement to be on a 5 point scale. Scale points indicating how much they wanted to parent to be involved were 5 (much more involved), 4 (a little more involved), 3 (it was just right), 2 (a little less involved), or 1 (much less involved).

Table 3

\begin{tabular}{cc}
\hline Desired Maternal and Paternal Involvement Domains \\
\hline Instrumental & Expressive \\
Developing responsibility & Mentoring \\
Developing competence & Caregiving \\
Ethical/moral development & Companionship \\
Advising & Intellectual development \\
Career development & Social development \\
Developing Independence & Emotional development \\
Being protective & Sharing activities/interests \\
Providing Income & Leisure/fun/play \\
School/homework & Physical development \\
Discipline & Spiritual development \\
\hline
\end{tabular}


The best model fits for the desired parental involvement scales were a two-factor solution for fathers and a two-factor solution for mothers. As was true for reported involvement, the desired involvement scales yielded isomorphic findings for mothers and fathers. The factors identified were an instrumental dimension and an expressive dimension of desired involvement (Finely, Mira, \& Schwartz, 2008). The domains that loaded onto each dimension are reported in Table 3. Parenting Behaviors, Divorce and Academic Outcomes.

The impact of parenting behaviors on child academic outcomes is firmly established in the literature with parental involvement and nurturance being positively correlated with academic achievement (Fitzpatrick \& Whitlock, 2004; Gonzalez-DeHass, Willems, \& Holbein, 2005; Jerry, 2014; Ming-Te \& Salem, 2014). Furthermore, the negative impact of divorce on child academic outcomes is a consistent finding in the literature (Barber, 1998; Bertram, 2006; Jeynes, 2002; Kelly \& Emery, 2003; McLanahan, 1999). Children from divorced families have lower math, reading and standardized test scores (Sun \& Li, 2002).

Controlling for socioeconomic status and income, compared to children in intact families, children from divorced families have lower academic performance (McLanahan, 1999). Approximately 25\% of children from divorced families have academic problems and children from divorced families are 2-3 times more likely to drop out of school (Kelly \& Emery, 2003). The relationship between academic outcomes and divorce is complex and is mediated by a variety of variables including parenting behaviors, peer relationships, and psychological variables. 


\section{Theoretical Perspective}

The present study examines how parenting behaviors of mothers and fathers, as reported by young adult children, affect child academic outcomes. Thus, what we are measuring is not the parenting behaviors themselves, but the young adult's perceptions of the parenting behavior of their mothers and fathers throughout their childhood and adolescence. The assumption is that the child's perception of parental nurturance and involvement, whether or not this perception is an accurate index of parental behavior, will predict child outcomes. Recent research supports that children's percetions of parenting are uniquely predictive of long term outcomes (Marquardt, 2005; Rohner \& Brittner, 2002; Schwartz \& Finley, 2009; Schwartz et al., 2009). This use of retrospective measures of parenting follows a phenomenological theoretical approach.

The phenomenological approach has been successfully employed by Rohner to develop his Parental Acceptance-Rejection Theory (PARTheory) which focuses on the warmth dimension of parenting (what we are calling nurturance) and the impact that parental warmth has on child adjustment. Today more than 1,700 studies are available on PARTheory (Rohner \& Brittner, 2002) and have demonstrated the efficacy of a phenomenological approach in predicting child outcomes.

Furthermore, a phenomenological approach has been successfully utilized crossculturally in several countries, including Mexico (Plunkett \& Bamaca-Gomez, 2003), England (Parker \&Barnett, 1988), China (Lau, 2006), Korea (Lee, 1998), India (Parmar \& Rohner, 2004) and Turkey (Varan, 2005). In fact, a phenomenological approach to measuring parenting behavior offers the advantage of allowing comparisons of studies conducted in various regions of the world, because the measures do not rely on any 
specific behavior or index of parenting that may be culturally determined, but rather on the overall perception or experience of the child. (For a more complete analysis of crosscultural research on perceived parental acceptance-rejection, see Khaleque \& Rohner, 2002, and Rohner, 1986).

In addition to Rohner's work, a phenomenological approach has been supported empirically by studies in the areas of family stress and self-concept, and “...research supporting these perspectives has demonstrated that individuals' perceptions are uniquely predictive of the experiences that individuals report” (Finley \& Schwartz, 2004 pg 145). Thus, when studying the influences of parenting behavior on child outcomes, higher effect sizes will likely be found for measures that use a phenomenological approach than for discrete behavioral measures of parenting behavior at a single point in time.

Evidence for the effectiveness of a phenomenological approach to examining parental behaviors and child academic outcomes was provided by a recent study of ninthgrade students whose reports of parental demands, responsiveness (similar to nurturance) and involvement predicted child academic achievement more significantly than parental reports (Paulson 1994). Findings of this sort raise important questions for policy makers and legislators when deciding upon child custody issues. The present standard of "best interest of the child" is often assessed from parental report and not the point of view of the child (Barnett \& Wilson, 2004; Finley, 2002; Finely \& Schwartz 2010). One can argue that this is a very questionable practice since "best interests of the child" may be best assessed through the use of retrospective measures from a phenomenological approach (Barnett \& Wilson, 2004; Boney, 2002; \& Finley \& Schwartz, 2004; 2010). 
Phenomenologically-focused retrospective measures have the added benefit that adults can report on phenomena that occurred in childhood with an adult level of maturity and understanding. Also, adults may be able to report their experiences more truthfully without the constraints of being under parent control or legal pressure in the context of a custody dispute (Finley \& Schwartz 2007; 2010; Schwartz \& Finely 2009). 


\section{CHAPTER 3 \\ RESEARCH QUESTIONS AND HYPOTHESES}

The present study was designed to examine parenting variables, specifically maternal and paternal nurturance and involvement, and how they impact academic outcomes for young adult male and female children in divorced and intact families. Research questions and hypotheses pertaining to parental nurturance will be described first, followed by those pertaining to parental involvement. Research questions and hypotheses tested are listed in Table 4.

\section{Parental Nurturance}

In regards to nurturance, the first research question is whether, overall, maternal nurturance and paternal nurturance affect child academic outcomes differentially. It is hypothesized that both maternal nurturance and paternal nurturance will correlate with academic outcomes, but that maternal nurturance and paternal nurturance will also offer unique contributions to child academic outcomes, meaning that maternal involvement and paternal involvement will not affect the same academic outcomes in the same way.

The second research question is whether the effects of maternal nurturance and paternal nurturance on child academic outcomes will vary by child gender and family form (intact versus divorced). It is hypothesized that nurturance effects will vary by both gender and family form; that is, that different effects of maternal nurturance versus paternal nurturance will be found for sons versus daughters in intact families and for sons and daughters in divorced families. 


\section{Parental Involvement}

In regards to parental involvement, the research questions are comparable to those for parental nurturance. The third research question of the present study is whether maternal involvement and paternal involvement will affect child academic outcomes differentially. As for nurturance, the research hypothesis is that maternal involvement and paternal involvement will be correlated with child academic outcomes, but will be differentially associated with academic outcomes, offering unique contributions to child academic outcomes.

Table 4 Research Questions and Hypotheses Research Questions Hypotheses Tested

1. Do maternal nurturance and paternal nurturance differentially affect child academic outcomes?

2. Do the effects of maternal nurturance and paternal nurturance on child academic outcomes vary as a function of child gender, family form, and child gender by family form?

3. Do maternal involvement and paternal involvement differentially affect child academic outcomes?

4. Do the effects of maternal involvement and paternal involvement on child academic outcomes vary as a function of child gender, family form, and child gender by family form? 1a. Maternal nurturance and paternal nurturance scores will each correlate with academic outcomes

1b. Maternal and paternal nurturance scores will offer unique contributions to child academic outcomes.

2. The effects of maternal nurturance and paternal nurturance will vary differentially as a function of both child gender and family form.

3a. Maternal involvement and paternal involvement scores will each correlate with academic outcomes

3.b. Maternal and paternal involvement scores will offer unique contributions to child academic outcomes.

4. The effects of maternal involvement and paternal involvement will vary differentially as a function of both child gender and family form. 
The fourth and final research question asks if the effects of maternal involvement and paternal involvement vary as a function of child gender and family form. Again, as for maternal and paternal nurturance, it is hypothesized that the effects of maternal involvement and paternal involvement will be different for males and females from intact versus divorced families. 


\section{CHAPTER 4}

\section{METHODS}

Sample

The sample for the study is comprised of a total of 1,714 university students from Florida International University ( $\mathrm{n}=1371)$ and Florida State University (n=343). Participants' ages ranged from 15 to 55 years, with 89\% being between the ages of 18 and 21. Three quarters of the ethnically diverse, but predominantly Hispanic (56\%), sample were female. Seventy-four percent of participants were born in the United States, but $66 \%$ of their parents were born abroad. Immigrant participants and parents were primarily from Central America, South America, and the Caribbean.

Over half of the sample (61\%), were from intact families, 21\% were from divorced families and the remaining participants were from other family forms including never married, deceased, adoptive, and stepfamilies. Of those participants reporting socioeconomic status (during the participant's adolescence), 14\% reported annual family incomes below $\$ 30,000 ; 25 \%$ of incomes were between $\$ 30,000$ and $\$ 50,000 ; 36 \%$ were between $\$ 50,000$ and $\$ 100,000 ; 15 \%$ were between $\$ 100,000$ and $\$ 150,000$; and $10 \%$ were above $\$ 150,000$. Forty-one percent of fathers and 37\% of mothers were college graduates, whereas $14 \%$ of fathers and $9 \%$ of mothers had not graduated high school. Procedure

Participants were recruited from introductory psychology classes and received course credit for their participation. Participation was voluntary, and each participant read and signed a consent form. Trained graduate or undergraduate student lab assistants read a scripted description of the purpose of the study to the participants and then 
administered the questionnaire. Items in the questionnaire were counterbalanced to control for sequence effects. The administration time for the entire assessment battery ranged from 20 to 30 minutes. After completing the questionnaire, participants were debriefed. Data were gathered between September 2004 and January 2006.

Measures

This section includes a description of the measures that were incorporated into the study questionnaire administered to participants. The complete questionnaire can be found in Appendix A.

Demographics. Participants reported on their age, year in school, gender ethnicity, household income level, place of residence, child's place of birth, and mother's and father's place of birth. Family form was also reported and participants indicated if their parents were never married, married, divorced, deceased, adoptive, or stepparents. Participants were able to report all relevant family forms and indicate their age during family form transitions.

Nurturant Fathering and Mothering Scales. The Nurturant Fathering and Mothering Scales (Mira 2006; Finley, Mira \& Schwartz 2008) consist of nine items each that are rated on a 5-point Likert type scale that participants used to characterize their relationships with the father figure and mother figure selected. Participants could select to rate their mother and father as figures as biological, adoptive, stepfather/mother, adoptive, or other father/mother figure. Possible scores on this measure range from 9 (highest nurturance score) to 45 (lowest nurturance score). The nurturance items for the father scale are listed are listed in Table X below. Wording of items for the mothering and fathering scales are identical, except for the words "mother” and "father." 
Table 5

Nurturant Fathering Scale

Nurturance Variable

Questionnaire Index Item

Enjoy How much do you think your father enjoyed being a father? (1) a great deal, (2) very much, (3) somewhat, (4) a little, (5) not at all

Support When you needed your father's support, was he there for you? (1) always, (2) often, (3) sometimes, (4) rarely (5) never

Energy Did your father have enough energy to meet your needs? (1) always, (2) often, (3) sometimes, (4) rarely (5) never

Confide Did you feel that you could confide in your father?

(1) always, (2) often, (3) sometimes, (4) rarely (5) never

Time

Was your father available to spend time with you in activities?

(1) always, (2) often, (3) sometimes, (4) rarely (5) never

Close $\quad$ How emotionally close were you to your father?

(1) extremely, (2) very, (3) somewhat, (4) a little, (5) not at all

Cronbach’s alpha coefficients for scores on the Nurturant Fathering Scales from prior research have ranged between .88 and .94 (Williams \& Finley, 1997; Finley \& Schwartz 2004; and Finley, Mira \& Schwartz 2008).

Mother and Father Involvement Scales. The Mother and Father Involvement Scales (Mira 2006; Finley, Mira \& Schwartz 2008) each list 20 domains of parental involvement (e.g., advising, caregiving, school/homework, spiritual). Each domain is listed between two blanks, where the participant is instructed to provide a reported involvement rating in the left-hand blank and a desired involvement rating in the righthand blank. For the reported involvement measure, participants were asked to indicate 
how involved, on a scale of 1 (not at all involved) to 5 (very involved), their mothers and fathers were in their lives.

Possible score totals for reported mother and father involvement range from 20 to 100. Internal consistency reliability tests for the Father Involvement Scale subscales revealed high Cronbach’s alpha statistics: Expressive Father Involvement= .91, Instrumental Father Involvement $=.90$, Mentoring/Advising Father Involvement $=.88$. The Mother Involvement Scale subscale also yielded high Cronbach’s alpha statistics: Expressive Mother Involvement $=.86$, Instrumental Mother Involvement $=.80$, and Mentoring/Advising Mother Involvement = .82 (Finley, Mira \& Schwartz 2008).

A curvilinear scale was used to measure desired mother involvement and desired father involvement as reported by adult children. Adult children rated their desired level of maternal involvement and desired level of paternal involvement on a 1 to 5 scale, with anchor points being 1 (wanted much less involvement), 3 (involvement was just right), and 5 (desired much more involvement). Cronbach’s alpha estimates for desired expressive father involvement $=.91$ and for desired instrumental father involvement $=$ .91. Internal consistency estimates for the desired mothering subscales yielded Cronbach’s alphas for desired expressive mother involvement $=.89$ and for desired instrumental mother involvement $=.88$ (Finley, Mira \& Schwartz 2008). Thus, internal consistency was high for the Involvement measures, as well as the Nurturance measures.

For analytic purposes, a statistical correction was employed with the desired involvement domain measures. The curvilinear scale was made to fit a linear model by only using values of 3.1 (a score of 3 being amount of involvement was just right) to 5 (wanted much more involvement). Thus, as employed in the current study, higher scores 
on this scale indicated that participants had desired more involvement from the parent than they actually received.

Academic Outcomes. There were 6 items in the questionnaire that measured academic outcomes. Participants reported their overall high school grade point average (GPA), and if they had been, on average, an A, B, C, or D student in high school. Similarly, participants reported their current college GPA (if applicable) and actual or anticipated average college grade. Academic satisfaction was rated on a 1 (very low) to 5 (very high) scale and academic importance was rated on a 1 (not at all important) to 4 (extremely important) scale. The academic outcome variables and how they were measured in the questionnaire are displayed in Table 6 below.

Table 6

Academic Outcome Variables

Outcome Variable Questionnaire Index Item

High School GPA Participants wrote in their high school GPA

High School Grade Participants circled an option from the question: In high school, I was mostly an "A" student, "B" student, “C” student, "D” student

College GPA Participants wrote in their college GPA (if applicable)

College Grade $\quad$ Participants circled an option from the question: In college, I am (or expect to be) mostly an A" student, "B" student, "C" student, "D" student

Academic Importance Participants rated how important academics are in their life on a scale of (1) not at all important, (2) somewhat important, (3) important, (4) extremely important

Academic Satisfaction Participants rated their overall satisfaction with their academic work on a scale of (1) very low, (2) low, (3) moderate, (4) high, (5) very high 


\section{CHAPTER 5}

\section{RESULTS}

Following are the results of analyses addressing the relations of parental nurturance and involvement to the academic outcome measures. Analyses related to nurturance effects are presented first, followed by those related to the effects of reported and desired parental involvement. Correlational analyses were the predominant mode of data analysis. In these analyses, both the magnitude and the patterning of correlations were of interest. The results of the correlational analyses were further assessed by rank ordering the significant results according to effect size. Lastly, the correlational analyses were internally replicated through a unique variance analysis (UVE). The UVE also served as a test for the unique contributions of mothering and fathering variables on child academic outcomes, split by child gender and family form.

\section{Maternal Nurturance and Paternal Nurturance and Academic Outcomes}

Initial analyses examined the correlations between mother nurturance and father nurturance scores to determine if these scores were correlated significantly in either family form (see Table 7). Only scores from participants in the intact and divorced family forms were included in the analyses. Participants who endorsed other family forms including stepfamilies, deceased parents, and parents who were never married were excluded from the analyses. The results of the correlation analysis revealed that maternal and paternal nurturance were not correlated in divorced families. In contrast, in intact families, maternal and paternal nurturance were significantly correlated, $r=.37$. Thus, the relation between maternal and paternal nurturance was impacted by family form. 
Table 7

Correlations of Maternal and Paternal Nurturance by Family Form

Intact Family Divorced Family

Correlation of Mother with

$(\mathrm{N}=1036)$

$(\mathrm{N}=429)$

$.37 * *$

$-.01$

Father Nurturance

Note: ${ }^{* *}$ Correlation is significant at $p<0.01$ level (2-tailed).

Research Question 1: Do maternal nurturance and paternal nurturance, overall, affect child academic outcomes differentially? To address the first research question, the relations of mother nurturance and father nurturance to emergent adults’ academic outcomes were examined. Mother nurturance and father nurturance scores were correlated with each of the six academic outcome variables.

Statistically significant Pearson $r$ correlations were found, more for maternal nurturance than for paternal nurturance, but the effects were relatively weak. None of the significant effects reached an $\mathrm{r}$ value of .20 or greater, the value required to delineate a small, but definite relationship between variables (Guilford, 1956; Cohen, 1969; Cohen, 1988, Bartz 1994; Hopkins, 1997). Thus when examining the data set overall, maternal nurturance effects seemed to be somewhat stronger, but neither maternal nurturance nor paternal nurturance were related substantially to emergent adult academic outcomes.

Table 8

\begin{tabular}{|c|c|c|c|c|c|c|}
\hline \multicolumn{7}{|c|}{ Correlations of Maternal Nurturance and Paternal Nurturance with Academic Outcomes } \\
\hline & HS GPA & HS Grade & Col GPA & Col Grade & Satisfaction & Importance \\
\hline $\begin{array}{c}\text { Mother } \\
\mathrm{N}\end{array}$ & $\begin{array}{l}.087^{* *} \\
(1624)\end{array}$ & $\begin{array}{l}.116^{* *} \\
\text { (1689) }\end{array}$ & $\begin{array}{l}.080 * * \\
(1124)\end{array}$ & $\begin{array}{l}.055^{*} \\
\text { (1681) }\end{array}$ & $\begin{array}{l}.117^{* *} \\
(1697)\end{array}$ & $\begin{array}{l}.132 * * \\
(1697)\end{array}$ \\
\hline $\begin{array}{c}\text { Father } \\
\mathrm{N}\end{array}$ & $\begin{array}{l}.045 \\
(1604)\end{array}$ & $\begin{array}{l}.030 \\
(1667)\end{array}$ & $\begin{array}{l}.118^{* *} \\
(1110)\end{array}$ & $\begin{array}{l}.041 \\
(1660)\end{array}$ & $\begin{array}{l}.067 * * \\
(1675)\end{array}$ & $\begin{array}{l}.034 \\
(1674)\end{array}$ \\
\hline
\end{tabular}

Note: $* *$ Correlation is significant at the $p<0.01$ level (2-tailed).

* Correlation is significant at the $p<0.05$ level (2-tailed). 
Research Question 2: Do the effects of maternal nurturance and paternal nurturance on child academic outcomes vary as a function of child gender, family form, and child gender by family form? To answer this research question, analyses first addressed the effects of child gender independent of family form, then the effects of family form, independent of gender. Finally, the effects for gender differentiated by family form were assessed.

Table 9 Correlations of Maternal Nurturance and Paternal Nurturance with Academic Outcomes by Child Gender

\begin{tabular}{|c|c|c|c|c|}
\hline \multirow{2}{*}{$\begin{array}{l}\text { Gender } \\
\text { Male }\end{array}$} & \multicolumn{2}{|c|}{ Academic Outcome } & \multirow{2}{*}{$\begin{array}{c}\text { Mother Nurturance } \\
.258^{* *}\end{array}$} & \multirow{2}{*}{$\begin{array}{c}\text { Father Nurturance } \\
.039\end{array}$} \\
\hline & Satisfaction & $r$ & & \\
\hline & & $\mathrm{N}$ & $(420)$ & $(412)$ \\
\hline & Importance & $r$ & $.147^{* *}$ & .083 \\
\hline & & $\mathrm{N}$ & $(420)$ & $(412)$ \\
\hline & HS GPA & $r$ & .054 & -.023 \\
\hline & & $\mathrm{N}$ & (398) & (391) \\
\hline & HS Grade & $r$ & .085 & -.019 \\
\hline & & $\mathrm{N}$ & (418) & $(410)$ \\
\hline & College GPA & r & .099 & .098 \\
\hline & & $\mathrm{N}$ & $(256)$ & $(251)$ \\
\hline & College Grade & $r$ & .090 & .021 \\
\hline & & $\mathrm{N}$ & (417) & $(410)$ \\
\hline \multirow[t]{12}{*}{ Female } & Satisfaction & $\mathrm{r}$ & $.107 * *$ & $.084^{* *}$ \\
\hline & & $\mathrm{N}$ & $(1275)$ & (1261) \\
\hline & Importance & $r$ & $.089 * *$ & .029 \\
\hline & & $\mathrm{N}$ & (1274) & (1260) \\
\hline & HS GPA & $\mathrm{r}$ & $.092 * *$ & $.079 * *$ \\
\hline & & $\mathrm{N}$ & (1225) & (1212) \\
\hline & HS Grade & $\mathrm{r}$ & $.125^{* *}$ & $.063 *$ \\
\hline & & $\mathrm{N}$ & $(1270)$ & (1256) \\
\hline & College GPA & $\mathrm{r}$ & $.070 *$ & $.129 * *$ \\
\hline & & $\mathrm{N}$ & $(867)$ & (858) \\
\hline & College Grade & $r$ & .044 & .054 \\
\hline & & $\mathrm{N}$ & (1263) & (1249) \\
\hline
\end{tabular}

Note: ${ }^{* *}$ Correlation is significant at the 0.01 level (2-tailed).

* Correlation is significant at the 0.05 level (2-tailed). 
Thus, in the first step, separate correlations were computed for sons and daughters to test for effects of child gender on the relationship between maternal nurturance and paternal nurturance and academic outcomes of emergent adult children. Again, statistically significant effects were found for both maternal and paternal nurturance on academic outcome variables, but only one relationship had an $r$ value supporting a scientifically definitive relation.

Table 10 Correlations of Maternal Nurturance and Paternal Nurturance with Academic Outcomes by Family Form

\begin{tabular}{lllll}
\hline Family Form & \multicolumn{2}{l}{ Academic Outcome } & Mother Nurturance & Father Nurturance \\
\hline Intact & Satisfaction & $r$ & $.165^{* *}$ & $.144^{* *}$ \\
& Importance & $r$ & $(1033)$ & $(1035)$ \\
& $\mathrm{N}$ & $.161^{* *}$ & $.097^{* *}$ \\
& & $(1035)$ & $(1034)$ \\
& HS GPA & $\mathrm{N}$ & $.108^{* *}$ & .032 \\
& & $(990)$ & $(989)$ \\
& HS Grade & $r$ & $.131^{* *}$ & .056 \\
& $\mathrm{~N}$ & $(1033)$ & $(1032)$ \\
& College GPA & $r$ & $.101^{* *}$ & $.133^{* *}$ \\
& $\mathrm{~N}$ & $(683)$ & $(682)$ \\
& College Grade & $r$ & $.072^{*}$ & $.074^{*}$ \\
& $\mathrm{~N}$ & $(1027)$ & $(1025)$ \\
\hline Divorced & Satisfaction & $r$ & .059 & -.016 \\
& $\mathrm{~N}$ & $(441)$ & $(429)$ \\
& Importance & $r$ & .092 & .012 \\
& $\mathrm{~N}$ & $(441)$ & $(429)$ \\
& HS GPA & $r$ & .017 & -.020 \\
& $\mathrm{~N}$ & $(423)$ & $(412)$ \\
& HS Grade & $r$ & $.098^{*}$ & .022 \\
& $\mathrm{~N}$ & $(440)$ & $(428)$ \\
& College GPA & $r$ & .054 & $.129^{*}$ \\
& $\mathrm{~N}$ & $(293)$ & $(288)$ \\
& College Grade & $r$ & .055 & -.013 \\
& $\mathrm{~N}$ & $(435)$ & $(425)$ \\
& &
\end{tabular}

Note: ${ }^{* *}$ Correlation is significant at the $p<0.01$ level (2-tailed).

* Correlation is significant at the $p<0.05$ level (2-tailed). 
In order to assess the moderating effects of family form, independent of gender, on the relationship between parental nurturance and child academic outcomes, data were split by family form into intact and divorced families. There were more statistically significant effects from the bivariate correlations for intact families than for divorced families, and more for mothers than for fathers within intact families, but again these were relatively weak effects. These results are presented in Table 10.

To address the major research question of the nurturance analyses about the relative contributions of maternal and paternal nurturance on sons and daughters from intact and divorced family forms, the data were split by gender and family form. Bivariate correlations were conducted between maternal nurturance and paternal nurturance and child academic outcomes separately for sons and daughters from divorced and intact family forms. The results of these analyses revealed significant findings, as can be seen in Tables 11 through 14.

In intact families, both maternal nurturance and paternal nurturance impacted child academic outcomes. For sons, there was a moderately significant effect for the outcome variable "importance of academics" that was consistent for mother nurturance and father nurturance (Table 11). For daughters from intact families, all $r$ values were less than .20 (Table 12). However, the consistent pattern of the findings across outcome variables in the same direction suggests a relevant finding. 
Table 11

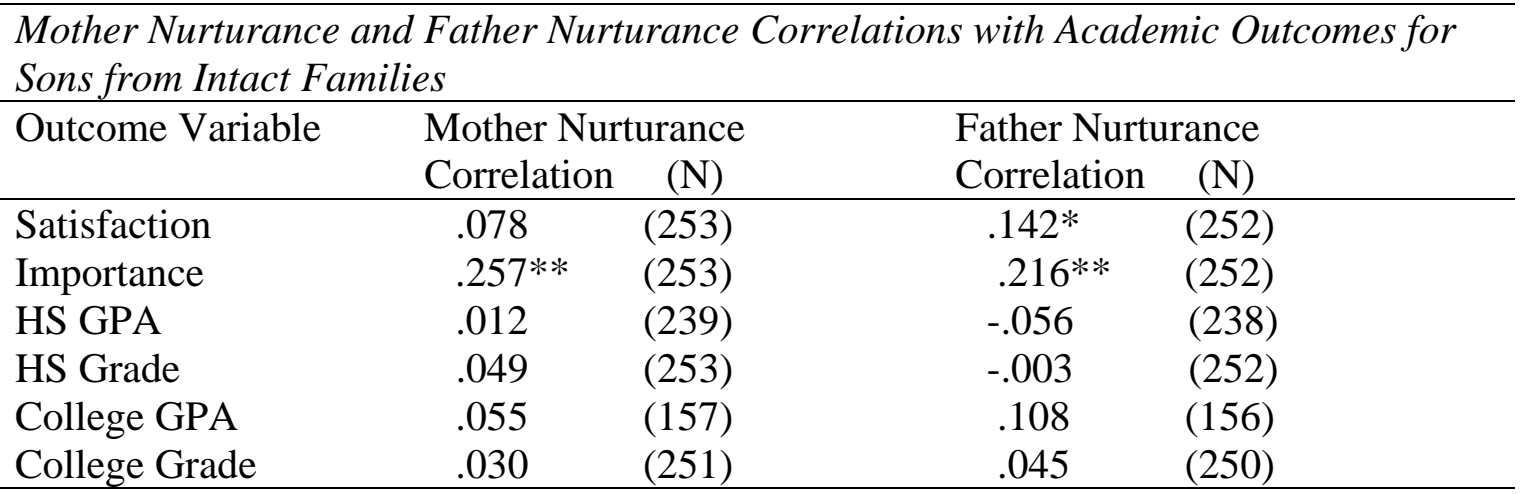

Note: ${ }^{* *}$ Correlation is significant at the $p<0.01$ level (2-tailed).

* Correlation is significant at the $p<0.05$ level (2-tailed).

Table 11

Mother Nurturance and Father Nurturance Correlations with Academic Outcomes for Daughters from Intact Families

\begin{tabular}{lcccc}
\hline Outcome Variable & \multicolumn{2}{c}{ Mother Nurturance } & \multicolumn{2}{c}{ Father Nurturance } \\
& Correlation & $(\mathrm{N})$ & $.146^{* *}$ & $(783)$ \\
\hline Satisfaction & $.186^{* *}$ & $(783)$ & .056 & $(782)$ \\
Importance & $.122^{* *}$ & $(782)$ & .058 & $(751)$ \\
HS GPA & $.125^{* *}$ & $(751)$ & $.082^{*}$ & $(777)$ \\
HS Grade & $.153^{* *}$ & $(777)$ & .138 & $(526)$ \\
College GPA & $.104^{* *}$ & $(526)$ & $.086^{* *}$ & $(775)$ \\
College Grade & $.081^{*}$ & $(776)$ & &
\end{tabular}

Note: ${ }^{* *}$ Correlation is significant at the $p<0.01$ level (2-tailed).

* Correlation is significant at the $p<0.05$ level (2-tailed).

There was a hint of a cross-gender effect in divorced families, with maternal nurturance being particularly impactful for sons (Table 13) and paternal nurturance being impactful for daughters (Table 14). However, the single statistically significant relation between father nurturance and daughter's college GPA was relatively weak, $r=.134, p<$. 05. 
Table 13

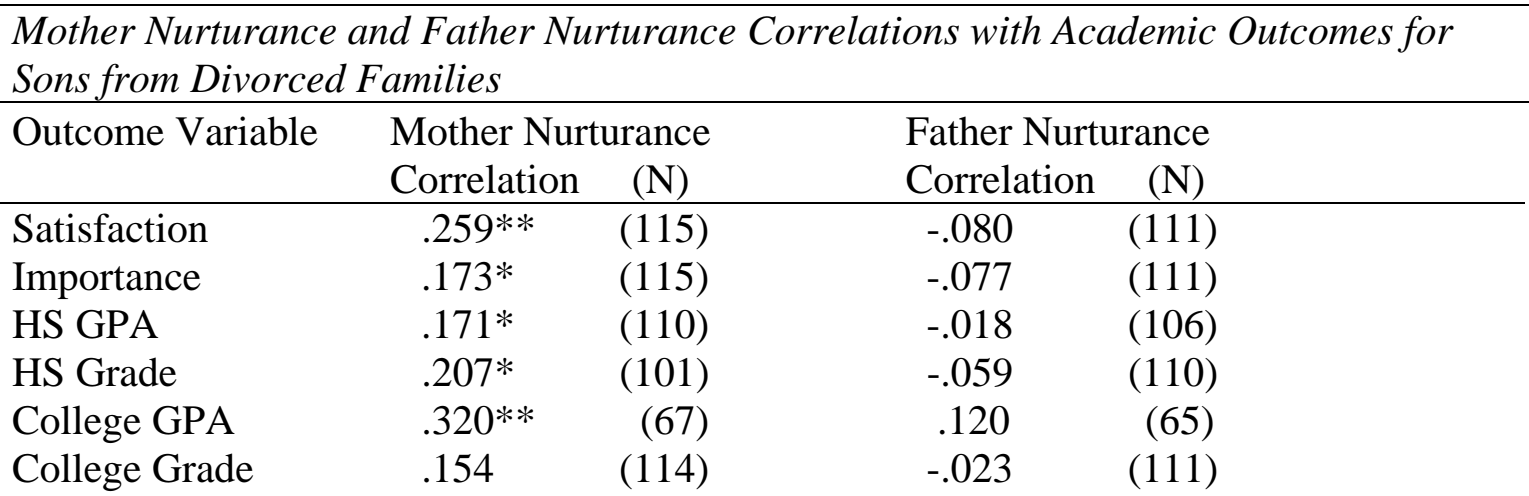

Note: ${ }^{* *}$ Correlation is significant at the $p<0.01$ level (2-tailed).

* Correlation is significant at the $p<0.05$ level (2-tailed).

Table 14

Mother Nurturance and Father Nurturance Correlations with Academic Outcomes for Daughters from Divorced Families

\begin{tabular}{lcccc}
\hline Outcome Variable & \multicolumn{2}{c}{ Mother Nurturance } & \multicolumn{2}{c}{ Father Nurturance } \\
& Correlation & $(\mathrm{N})$ & Correlation & $(\mathrm{N})$ \\
\hline Satisfaction & .007 & $(352)$ & .020 & $(317)$ \\
Importance & .076 & $(325)$ & .076 & $(317)$ \\
HS GPA & -.016 & $(312)$ & .013 & $(305)$ \\
HS Grade & .082 & $(325)$ & .021 & $(317)$ \\
College GPA & -.009 & $(225)$ & $.134^{*}$ & $(222)$ \\
College Grade & .029 & $(320)$ & .007 & $(313)$ \\
\hline
\end{tabular}

Note: ${ }^{* *}$ Correlation is significant at the $p<0.01$ level (2-tailed).

* Correlation is significant at the $p<0.05$ level (2-tailed).

Surprisingly, no significant correlations were found between mother nurturance and daughters' academic outcomes in divorced family forms. Similarly, no significant correlations were found between father nurturance and sons' academic outcomes in divorced families. Thus, in divorced families, it was the opposite sex parent's nurturance that affected the present college GPA of emergent adult children with the strongest relations being between mother nurturance and academic outcomes for sons from divorced families, especially their college GPAs and satisfaction with their academic work. 


\section{Maternal Involvement and Paternal Involvement and Academic Outcomes}

As for the parental nurturance terms, initial analyses for parental involvement variables examined the correlation between maternal involvement and paternal involvement in intact and divorced family forms. First the relationship between reported maternal and paternal involvement variables was examined (Table 15).

Table 15

Correlations of Reported Maternal and Paternal Involvement by Family Form

\begin{tabular}{lccccc}
\hline Family & & & $\begin{array}{c}\text { Paternal } \\
\text { Instrumental }\end{array}$ & $\begin{array}{c}\text { Paternal } \\
\text { Expressive }\end{array}$ & $\begin{array}{c}\text { Paternal } \\
\text { Mentoring/Advising }\end{array}$ \\
\hline Intact & Maternal & $\mathrm{r}$ & $.438^{* *}$ & $.455^{* *}$ & $.381^{* *}$ \\
& Instrumental & $\mathrm{N}$ & $(1029)$ & $(1026)$ & $(1027)$ \\
& Maternal & $\mathrm{r}$ & $.480^{* *}$ & $.473^{* *}$ & $.413^{* *}$ \\
& Expressive & $\mathrm{N}$ & $(1035)$ & $(1031)$ & $(1030)$ \\
& Maternal & $\mathrm{r}$ & $.368^{* *}$ & $.348^{* *}$ & $.320^{* *}$ \\
& Protective/Caregiving & $\mathrm{N}$ & $(1035)$ & $(1031)$ & $(1030)$ \\
\hline Divorced & Maternal & $\mathrm{r}$ & -.040 & -.029 & -.074 \\
& Instrumental & $\mathrm{N}$ & $(403)$ & $(402)$ & $(403)$ \\
& Maternal & $\mathrm{r}$ & .051 & .027 & .007 \\
& Expressive & $\mathrm{N}$ & $(404)$ & $(401)$ & $(402)$ \\
& Maternal & $\mathrm{r}$ & -.054 & -.065 & -.089 \\
& Protective/Caregiving & $\mathrm{N}$ & $(403)$ & $(401)$ & $(402)$
\end{tabular}

Note: ${ }^{* *}$ Correlation is significant at the $p<0.01$ level (2-tailed).

The results of these correlations were consistent with the results for the parental nurturance variables. In intact families, reported maternal involvement and reported paternal involvement were significantly correlated. In divorced families, reported maternal involvement and reported paternal involvement were not correlated. Therefore, the relationships among reported parenting involvement variables were impacted by family form. 
Next, the relationships between desired maternal involvement and desired paternal involvement were examined, split by family form (Table 16). Although significant correlations were found for desired parental involvement in both intact and divorced families, the sizes of the correlations were significantly weaker for divorced families yielding the consistent finding that parenting variables are impacted by family form.

Table 16

\begin{tabular}{ccccc}
\hline \multicolumn{4}{l}{ Correlations of Desired Maternal and Paternal Involvement by Family Form } \\
\hline Family & & & $\begin{array}{c}\text { Desired Paternal } \\
\text { Instrumental }\end{array}$ & $\begin{array}{c}\text { Desired Paternal } \\
\text { Expressive }\end{array}$ \\
\hline Form & & & $.758^{* *}$ & $.584^{* *}$ \\
& Desired Maternal & $\mathrm{r}$ & $(939)$ & $(939)$ \\
& Instrumental & $\mathrm{N}$ & $.693^{* *}$ & $.629^{* *}$ \\
& Desired Maternal & $\mathrm{r}$ & $(939)$ & $(939)$ \\
\cline { 2 - 5 } Divorced & Expressive & $\mathrm{N}$ & $.268^{* *}$ & $.211^{* *}$ \\
& Desired Maternal & $\mathrm{r}$ & $(365)$ & $(365)$ \\
& Instrumental & $\mathrm{N}$ & $.255^{* *}$ & $.241^{* *}$ \\
& Desired Maternal & $\mathrm{r}$ & $(365)$ & $(365)$ \\
\hline
\end{tabular}

Note: ${ }^{* *}$ Correlation is significant at the $p<0.01$ level (2-tailed).

Research Question 3: Do maternal involvement and paternal involvement differentially affect child academic outcomes? Correlational analyses were conducted to test the relationship between maternal involvement and paternal involvement, both reported and desired, and child academic outcome variables. The results of these correlational analyses are depicted in Table 17 and Table 18. 
Table 17

\begin{tabular}{cccccccc}
\hline \multicolumn{10}{c}{ Correlations of Reported Maternal and Paternal Involvement with Academic Outcomes } \\
\hline \multicolumn{1}{c}{ HS } & HS & Col & Col & Satisfactio & Importance \\
& & GPA & Grade & Grade & GPA & n & \\
\hline Maternal & $\mathrm{r}$ & $.147^{* *}$ & $.173^{* *}$ & .046 & .051 & $.163^{* *}$ & $.181^{* *}$ \\
Instrumental & $\mathrm{N}$ & $(1372)$ & $(1430)$ & $(1422)$ & $(946)$ & $(1434)$ & $(1433)$ \\
Maternal & $\mathrm{r}$ & $.106^{* *}$ & $.134^{* *}$ & $.058^{*}$ & $.092^{* *}$ & $.143^{* *}$ & $.159^{* *}$ \\
Expressive & $\mathrm{N}$ & $(1381)$ & $(1439)$ & $(1428)$ & $(952)$ & $(1443)$ & $(1442)$ \\
Maternal & $\mathrm{r}$ & $.071^{* *}$ & $.074^{* *}$ & .036 & .022 & $.067^{*}$ & $.104^{* *}$ \\
Protective/ & $\mathrm{N}$ & $(1379)$ & $(1437)$ & $(1427)$ & $(950)$ & $(1441)$ & $(1440)$ \\
Caregiving & & & & & & & \\
\hline Paternal & $\mathrm{r}$ & $.065^{*}$ & $.089^{* *}$ & .033 & $.107^{* *}$ & $.089^{* *}$ & $.079^{* *}$ \\
Instrumental & $\mathrm{N}$ & $(1378)$ & $(1440)$ & $(1425)$ & $(952)$ & $(1440)$ & $(1439)$ \\
Paternal & $\mathrm{r}$ & .046 & $.052^{*}$ & .050 & $.114^{* *}$ & $.123^{* *}$ & $.076^{* *}$ \\
Expressive & $\mathrm{N}$ & $(1371)$ & $(1429)$ & $(1420)$ & $(945)$ & $(1433)$ & $(1432)$ \\
Paternal & $\mathrm{r}$ & .040 & .049 & .041 & $.097^{* *}$ & $.083^{* *}$ & $.066^{*}$ \\
Mentoring/ & $\mathrm{N}$ & $(1371)$ & $(1429)$ & $(1420)$ & $(947)$ & $(1433)$ & $(1432)$ \\
Advising & & & & & \\
Note: **Correlation is significant at the $p<0.01$ level (2-tailed). & & \\
* Correlation is significant at the $p<0.05$ level (2-tailed). &
\end{tabular}

Table 18

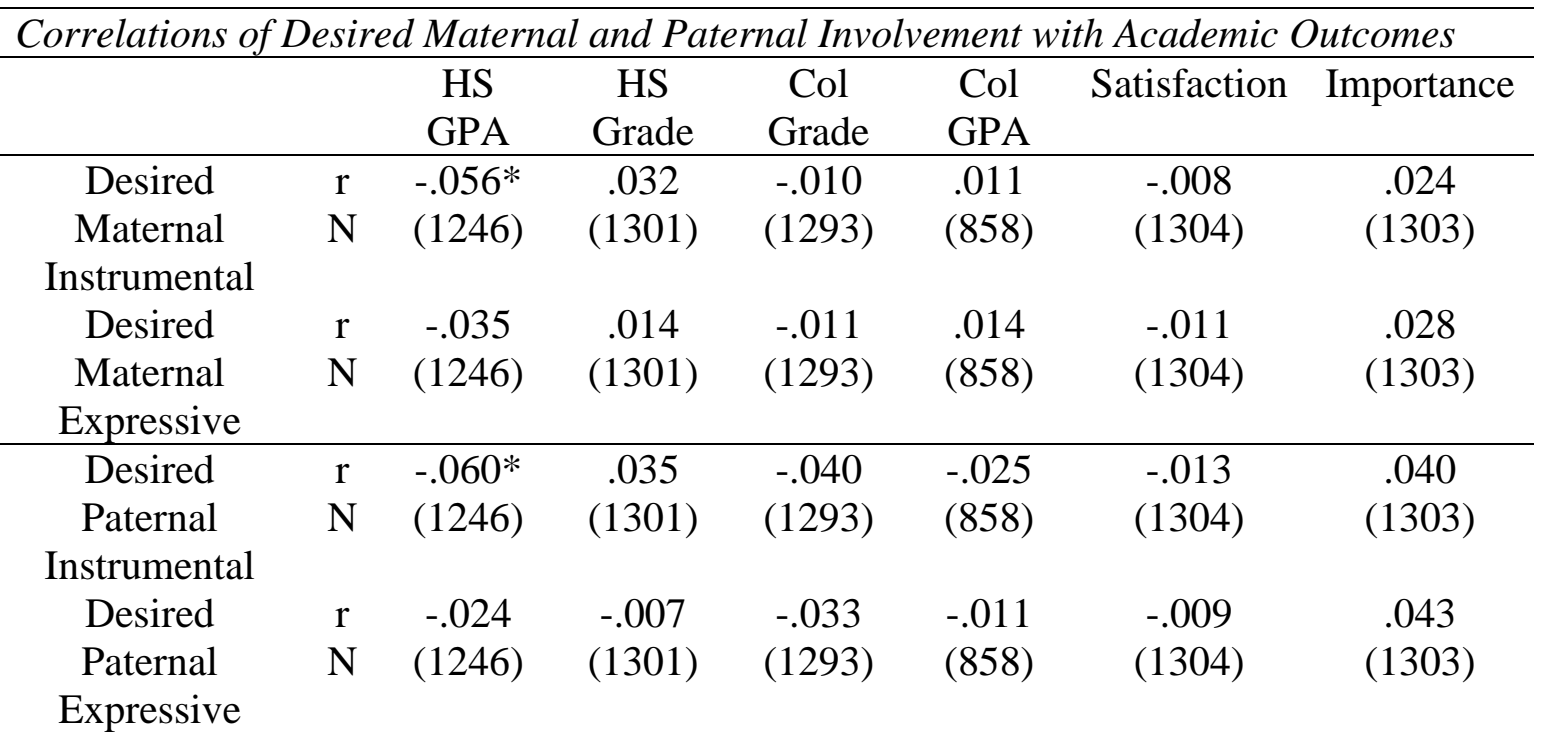

Note: * Correlation is significant at the $p<0.05$ level (2-tailed).

The results of these correlational analyses yielded only marginally significant results. These results are inconclusive regarding whether maternal involvement variables 
and paternal involvement variables differentially affect academic outcomes, affirming the need to assess variation by gender and family form.

Research Question 4: Do the effects of maternal involvement and paternal involvement on child academic outcomes vary as a function of child gender, family form, and child gender by family form? Analyses for this hypothesis first addressed the effects for child gender independent of family form, then the effects for family form, independent of gender. Finally, the effects for gender differentiated by family form were assessed.

Thus, initially, separate correlations were computed for sons and daughters to test for effects of child gender on the relationships of maternal involvement and paternal involvement to child academic outcomes. The correlations for the reported involvement variables and the desired involvement variables with academic outcomes split by child gender are presented in tables 19 and 20.

The results of these correlational analyses yielded primarily marginally significant results, although stronger associations were found for reported maternal involvement for male participants. Three correlations reached a magnitude of .20 or above. These were between maternal instrumental involvement an high school grades, maternal instrumental involvement and perceived importance of academics, and maternal expressive involvement and academic importance. None of the desired involvement correlations reached meaningful significance. 
Table 19

\begin{tabular}{|c|c|c|c|c|c|c|c|c|}
\hline \multicolumn{9}{|c|}{$\begin{array}{l}\text { Correlations of Reported } M \\
\text { by Child Gender }\end{array}$} \\
\hline Child & & & HS & HS & Col & Col & Satisfaction & Importance \\
\hline Gender & & & GPA & Grade & Grade & GPA & & \\
\hline \multirow[t]{12}{*}{ Male } & Maternal & $\mathrm{r}$ & -.058 & $.202^{* *}$ & $.106^{*}$ & .123 & $198^{* *}$ & $.225 * *$ \\
\hline & Instrumental & $\mathrm{N}$ & (302) & (353) & (352) & $(214)$ & (354) & (354) \\
\hline & Maternal & $\mathrm{r}$ & .045 & .063 & .023 & $.173^{*}$ & $149 * *$ & $.212 * *$ \\
\hline & Expressive & $\mathrm{N}$ & (335) & (353) & (352) & (214) & (354) & (354) \\
\hline & Maternal & $r$ & .069 & $.133^{*}$ & .026 & .086 & $.108 *$ & $.155^{* *}$ \\
\hline & $\begin{array}{l}\text { Protective/ } \\
\text { Caregiving }\end{array}$ & $\mathrm{N}$ & (335) & (353) & (352) & $(214)$ & (354) & (354) \\
\hline & Paternal & $r$ & -.034 & -.028 & .045 & .119 & .038 & $.119 *$ \\
\hline & Involvement & $\mathrm{N}$ & (302) & (354) & (353) & $(215)$ & (355) & (355) \\
\hline & Paternal & $\mathrm{r}$ & -.029 & -.025 & .050 & .106 & .103 & $.138 * *$ \\
\hline & Expressive & $\mathrm{N}$ & (335) & (353) & (352) & (214) & (354) & (354) \\
\hline & Paternal & $\mathrm{r}$ & -.041 & -.066 & .049 & .076 & .098 & .020 \\
\hline & $\begin{array}{l}\text { Mentoring/ } \\
\text { Advising }\end{array}$ & $\mathrm{N}$ & (334) & (353) & (351) & $(214)$ & (353) & (353) \\
\hline \multirow[t]{12}{*}{ Female } & Maternal & $r$ & $.110^{* *}$ & $.135 *$ & .011 & .008 & $.135 * *$ & $.139 * *$ \\
\hline & Instrumental & $\mathrm{N}$ & (1036) & (1076) & (1069) & $(731)$ & (1079) & (1078) \\
\hline & Maternal & $\mathrm{r}$ & $.088 * *$ & $.125^{* *}$ & .053 & .049 & $.123 * *$ & $.114 * *$ \\
\hline & Expressive & $\mathrm{N}$ & (1045) & (1085) & (1075) & (737) & (1088) & (1087) \\
\hline & Maternal & $\mathrm{r}$ & $.068 *$ & .051 & .037 & -.003 & .053 & $.084 * *$ \\
\hline & $\begin{array}{l}\text { Protective/ } \\
\text { Caregiving }\end{array}$ & $\mathrm{N}$ & (1043) & (1083) & (1074) & $(735)$ & (1086) & (1085) \\
\hline & Paternal & $r$ & $.080^{*}$ & $.106^{* *}$ & .032 & $.107^{*}$ & $.108^{* *}$ & $.073^{*}$ \\
\hline & Involvement & $\mathrm{N}$ & (1084) & (1081) & (1071) & (736) & (1084) & (1083) \\
\hline & Paternal & $\mathrm{r}$ & $.071 *$ & $.087^{* *}$ & -.013 & -.044 & $.134 * *$ & .060 \\
\hline & Expressive & $\mathrm{N}$ & (1078) & (1075) & (974) & (663) & (1078) & (1077) \\
\hline & Paternal & $r$ & $.079 *$ & $.109 * *$ & .047 & $.111^{* *}$ & $.112 * *$ & $.071^{*}$ \\
\hline & $\begin{array}{l}\text { Mentoring/ } \\
\text { Advising }\end{array}$ & $\mathrm{N}$ & (1036) & (1076) & (1068) & $(732)$ & (1079) & 1078 \\
\hline
\end{tabular}

Note: ${ }^{* *}$ Correlation is significant at the $p<0.01$ level (2-tailed).

* Correlation is significant at the $p<0.05$ level (2-tailed). 
Table 20

\begin{tabular}{|c|c|c|c|c|c|c|c|c|}
\hline \multicolumn{9}{|c|}{$\begin{array}{l}\text { Correlations of Desired Mat } \\
\text { Child Gender }\end{array}$} \\
\hline \multirow{2}{*}{$\begin{array}{l}\text { Child } \\
\text { Gender }\end{array}$} & & & HS & HS & Col & Col & \multirow[t]{2}{*}{ Satisfaction } & \multirow[t]{2}{*}{ Importance } \\
\hline & & & GPA & Grade & Grade & GPA & & \\
\hline \multirow[t]{11}{*}{ Male } & Desired & $r$ & -.058 & .033 & -.038 & .009 & -.019 & .063 \\
\hline & Maternal & $\mathrm{N}$ & (302) & (319) & (318) & (194) & (320) & (320) \\
\hline & Desired & $\mathrm{r}$ & -.050 & .016 & -.061 & .018 & -.035 & .062 \\
\hline & Maternal & $\mathrm{N}$ & 302 & (319) & (318) & (194) & (320) & (320) \\
\hline & Instrumental & & & & & & & \\
\hline & Desired & $\mathrm{r}$ & -.034 & .021 & -.092 & .040 & .047 & .078 \\
\hline & Paternal & $\mathrm{N}$ & (302) & (319) & (318) & (194) & (320) & (320) \\
\hline & Involvement & & & & & & & \\
\hline & Desired & $\mathrm{r}$ & .011 & -.061 & -.069 & .067 & .044 & .082 \\
\hline & Paternal & $\mathrm{N}$ & (302) & (319) & (318) & (194) & (320) & (320) \\
\hline & Expressive & & & & & & & \\
\hline \multirow[t]{11}{*}{ Female } & Desired & $\mathrm{r}$ & -.056 & .030 & -.002 & .012 & -.022 & .013 \\
\hline & Maternal & $\mathrm{N}$ & (943) & (981) & (974) & (663) & (983) & (982) \\
\hline & Involvement & & & & & & & \\
\hline & Desired & $\mathrm{r}$ & -.048 & .030 & .010 & .002 & -.011 & .005 \\
\hline & Maternal & $\mathrm{N}$ & (943) & (981) & (974) & (663) & (983) & (982) \\
\hline & Instrumental & & & & & & & \\
\hline & Desired & $\mathrm{r}$ & $-.070 *$ & .041 & -.022 & -.046 & -.034 & .025 \\
\hline & Paternal & $\mathrm{N}$ & (943) & (981) & (974) & (663) & (983) & (982) \\
\hline & Involvement & & & & & & & \\
\hline & Desired & $\mathrm{r}$ & -.055 & .035 & -.013 & -.044 & -.037 & .013 \\
\hline & Paternal & $\mathrm{N}$ & $(943)$ & (981) & (974) & (663) & (983) & (982) \\
\hline
\end{tabular}

Note: $* *$ Correlation is significant at the $p<0.01$ level (2-tailed).

* Correlation is significant at the $p<0.05$ level (2-tailed).

To further examine the relationship between parental involvement, reported and desired, and academic outcomes, the data were split by family form. The correlations for the reported involvement variables and academic outcomes split by family form are depicted in Table 21. The correlations for the desired involvement variables and academic outcomes split by family form are depicted in Table 22.

The results were parallel to those for nurturance. Both maternal and paternal reported involvement scores were associated with academic outcomes in intact families, but the correlations were generally weak. There were a few more statistically significant 
but weak correlations for maternal involvement than for paternal involvement in divorced families, but the results for divorced families were largely non-significant. There were no significant findings for desired involvement.

Table 21

Correlations of Reported Maternal and Paternal Involvement with Academic Outcomes by Family Form

\begin{tabular}{|c|c|c|c|c|c|c|c|c|}
\hline $\begin{array}{l}\text { Family } \\
\text { Form }\end{array}$ & & & $\begin{array}{c}\text { HS } \\
\text { GPA }\end{array}$ & $\begin{array}{c}\text { HS } \\
\text { Grade }\end{array}$ & $\begin{array}{c}\text { Col } \\
\text { Grade }\end{array}$ & $\begin{array}{l}\text { Col } \\
\text { GPA }\end{array}$ & Satisfaction & Importance \\
\hline \multirow[t]{12}{*}{ Intact } & Maternal & $\mathrm{r}$ & $.157 * *$ & $.172^{* *}$ & $.106^{*}$ & $.089 *$ & $.211 * *$ & $.189 * *$ \\
\hline & Instrumental & $\mathrm{N}$ & (983) & (1026) & (352) & (679) & (1029) & (1028) \\
\hline & Maternal & $\mathrm{r}$ & $.108^{* *}$ & $.136 * *$ & $.063^{*}$ & $.095 *$ & $.181^{* *}$ & $.177^{* *}$ \\
\hline & Expressive & $\mathrm{N}$ & (991) & (1027) & (352) & (684) & (1037) & (1036) \\
\hline & Maternal & $\mathrm{r}$ & . 105 & $.092 * *$ & .052 & .034 & $.094 * *$ & $.119 * *$ \\
\hline & $\begin{array}{l}\text { Protective/ } \\
\text { Caregiving }\end{array}$ & $\mathrm{N}$ & (990) & (1033) & (1026) & (683) & (1036) & (1035) \\
\hline & Paternal & $\mathrm{r}$ & .051 & $.099 * *$ & .035 & .063 & $.147 * *$ & $.154^{* *}$ \\
\hline & Instrumental & $\mathrm{N}$ & (989) & (1032) & (1025) & (683) & (1035) & (1034) \\
\hline & Paternal & $\mathrm{r}$ & .026 & $.074 *$ & .054 & $.095 *$ & $.190 * *$ & $.129 * *$ \\
\hline & Expressive & $\mathrm{N}$ & (985) & (1028) & (1022) & (679) & (1031) & (1030) \\
\hline & Paternal & $\mathrm{r}$ & .020 & .074 & $.064^{*}$ & .070 & $.138 * *$ & $.113^{* *}$ \\
\hline & $\begin{array}{l}\text { Mentoring/ } \\
\text { Advising }\end{array}$ & $\mathrm{N}$ & (984) & (1027) & (1021) & (680) & (1030) & (1029) \\
\hline \multirow[t]{12}{*}{ Divorced } & Maternal & $\mathrm{r}$ & $.114^{*}$ & $.171^{* *}$ & .023 & -.041 & .065 & $.172 * *$ \\
\hline & Instrumental & $\mathrm{N}$ & (389) & (1076) & (401) & (267) & (405) & (405) \\
\hline & Maternal & $\mathrm{r}$ & .080 & $.125^{*}$ & .038 & .068 & .058 & $.128 *$ \\
\hline & Expressive & $\mathrm{N}$ & (390) & (405) & (401) & 268 & (406) & (406) \\
\hline & Maternal & $\mathrm{r}$ & -.015 & .032 & -.066 & -.031 & .027 & $.098^{*}$ \\
\hline & $\begin{array}{l}\text { Protective/ } \\
\text { Caregiving }\end{array}$ & $\mathrm{N}$ & (389) & (404) & (401) & (267) & (405) & (405) \\
\hline & Paternal & $\mathrm{r}$ & .021 & .006 & .003 & $.142 *$ & .039 & .028 \\
\hline & Instrumental & $\mathrm{N}$ & (389) & $(404)$ & $(400)$ & (269) & (405) & (405) \\
\hline & Paternal & $\mathrm{r}$ & .027 & -.014 & .021 & $.124 *$ & .012 & .006 \\
\hline & Expressive & $\mathrm{N}$ & (386) & (401) & (398) & (266) & (402) & (402) \\
\hline & Paternal & $\mathrm{r}$ & .014 & -.018 & -.023 & .112 & .002 & .017 \\
\hline & $\begin{array}{l}\text { Mentoring/ } \\
\text { Advising }\end{array}$ & $\mathrm{N}$ & (387) & $(402)$ & (399) & (267) & (403) & (403) \\
\hline
\end{tabular}

Note: $* *$ Correlation is significant at the $p<0.01$ level (2-tailed).

* Correlation is significant at the $p<0.05$ level (2-tailed). 
Table 22

Correlations of Desired Maternal and Paternal Involvement with Academic Outcomes by Family Form

\begin{tabular}{|c|c|c|c|c|c|c|c|c|}
\hline $\begin{array}{c}\text { Family } \\
\text { Form }\end{array}$ & & & $\begin{array}{c}\text { HS } \\
\text { GPA }\end{array}$ & $\begin{array}{c}\text { HS } \\
\text { Grade }\end{array}$ & $\begin{array}{c}\text { Col } \\
\text { Grade } \\
\end{array}$ & $\begin{array}{c}\text { Col } \\
\text { GPA }\end{array}$ & Satisfaction & Importance \\
\hline \multirow[t]{12}{*}{ Intact } & Desired & $\mathrm{r}$ & -.034 & .004 & -.036 & .012 & -.002 & .028 \\
\hline & Maternal & $\mathrm{N}$ & (896) & (937) & (932) & (616) & (939) & (938) \\
\hline & Involvement & & & & & & & \\
\hline & Desired & $\mathrm{r}$ & -.002 & -.023 & -.048 & .035 & -.011 & .016 \\
\hline & Maternal & $\mathrm{N}$ & (896) & (937) & $(932)$ & (616) & (939) & (938) \\
\hline & Instrumental & & & & & & & \\
\hline & Desired & $r$ & -.037 & .009 & -.063 & .007 & .018 & .027 \\
\hline & Paternal & $\mathrm{N}$ & (896) & (937) & (932) & (616) & (939) & (938) \\
\hline & Involvement & & & & & & & \\
\hline & Desired & $r$ & .018 & -.039 & -.038 & .005 & .009 & .021 \\
\hline & Paternal & $\mathrm{N}$ & (896) & (937) & (932) & (616) & (939) & (938) \\
\hline & Expressive & & & & & & & \\
\hline \multirow[t]{12}{*}{ Divorced } & Desired & $r$ & -.093 & .094 & .047 & .022 & -.026 & .007 \\
\hline & Maternal & $\mathrm{N}$ & $(350)$ & (364) & (361) & (242) & (365) & (365) \\
\hline & Involvement & & & & & & & \\
\hline & Desired & $\mathrm{r}$ & -.094 & .100 & .070 & -.018 & -.013 & .050 \\
\hline & Maternal & $\mathrm{N}$ & $(350)$ & (364) & (361) & (242) & (365) & (365) \\
\hline & Instrumental & & & & & & & \\
\hline & Desired & $r$ & -.070 & .077 & -.010 & -.070 & -.090 & .050 \\
\hline & Paternal & $\mathrm{N}$ & (350) & (364) & (361) & (242) & (365) & (365) \\
\hline & Involvement & & & & & & & \\
\hline & Desired & $\mathrm{r}$ & -.064 & .041 & -.045 & -.019 & -.057 & .068 \\
\hline & Paternal & $\mathrm{N}$ & $(350)$ & (364) & (361) & (242) & (365) & (365) \\
\hline & Expressive & & & & & & & \\
\hline
\end{tabular}

As the final step in testing the hypothesis that the effects of parental involvement would vary by both gender and family form, correlation analyses were performed for the reported and desired involvement scales utilizing the gender and family form split. Each involvement subscale for mother and father involvement, reported and desired, was correlated with each of the academic outcome variables.

The results of these analyses can be seen in Tables 23 through 30. These tables include the correlations from the previous analyses of parental nurturance, so that the overall patterning of the correlations between parenting and academic outcomes can be viewed. 
The reported and desired involvement correlations yielded a number of statistically significant but relatively weak results. The results showed a consistent pattern, however, with the strongest effects emerging for the relations between mothering and academic outcomes for sons in divorced families (Table 23).

Table 23

\begin{tabular}{|c|c|c|c|c|c|c|c|c|c|c|c|c|}
\hline \multicolumn{13}{|c|}{ Impact of Mothering on Sons from Divorced Families } \\
\hline \multirow{2}{*}{$\begin{array}{l}\text { Maternal } \\
\text { Parenting } \\
\text { variable }\end{array}$} & \multicolumn{2}{|c|}{ HS GPA } & \multicolumn{2}{|c|}{ HS Grade } & \multicolumn{2}{|c|}{$\begin{array}{c}\text { College } \\
\text { GPA }\end{array}$} & \multicolumn{2}{|c|}{$\begin{array}{l}\text { College } \\
\text { Grade }\end{array}$} & \multicolumn{2}{|c|}{ Satisfaction } & \multicolumn{2}{|c|}{ Importance } \\
\hline & r & $\mathrm{N}$ & r & $\mathrm{N}$ & r & $\mathrm{N}$ & $\mathrm{r}$ & $\mathrm{N}$ & $\mathrm{r}$ & $\mathrm{N}$ & $\mathrm{r}$ & $\mathrm{N}$ \\
\hline Nurturance & .171 & 110 & $.207 *$ & 114 & $.320 * *$ & 67 & .154 & 114 & $.259 * *$ & 115 & .173 & 115 \\
\hline $\begin{array}{l}\text { Instrumental } \\
\text { Involvement }\end{array}$ & $.270 * *$ & 109 & $.307 * *$ & 113 & .068 & 66 & $.158 * *$ & 113 & .110 & 114 & $.159 *$ & 114 \\
\hline $\begin{array}{l}\text { Expressive } \\
\text { Involvement }\end{array}$ & $.256 * *$ & 109 & $.204^{*}$ & 113 & $.279 *$ & 66 & .081 & 113 & .147 & 114 & .153 & 114 \\
\hline $\begin{array}{l}\text { Mentoring } \\
\text { Involvement }\end{array}$ & $.310^{*}$ & 110 & $.343^{*}$ & 114 & -.004 & 67 & .023 & 113 & .110 & 115 & .137 & 114 \\
\hline $\begin{array}{l}\text { Desired } \\
\text { Instrumental }\end{array}$ & $-.227 *$ & 64 & $-.308 * *$ & 68 & -.096 & 45 & -.151 & 68 & -.136 & 68 & .081 & 68 \\
\hline $\begin{array}{l}\text { Desired } \\
\text { Expressive }\end{array}$ & -.169 & 80 & $-.230 *$ & 83 & $-.236^{*}$ & 50 & -.140 & 82 & $-.224 *$ & 83 & -.010 & 83 \\
\hline
\end{tabular}

Table 24

\begin{tabular}{|c|c|c|c|c|c|c|c|c|c|c|c|c|}
\hline \multicolumn{13}{|c|}{ Impact of Mothering on Sons from Intact Families } \\
\hline \multirow{2}{*}{$\begin{array}{l}\text { Maternal } \\
\text { Parenting } \\
\text { variable }\end{array}$} & \multicolumn{2}{|c|}{ HS GPA } & \multicolumn{2}{|c|}{ HS Grade } & \multicolumn{2}{|l|}{$\begin{array}{l}\text { College } \\
\text { GPA }\end{array}$} & \multicolumn{2}{|l|}{$\begin{array}{l}\text { College } \\
\text { Grade }\end{array}$} & \multicolumn{2}{|c|}{ Satisfaction } & \multicolumn{2}{|c|}{ Importance } \\
\hline & $\mathrm{r}$ & $\mathrm{N}$ & $\mathrm{r}$ & $\mathrm{N}$ & $\mathrm{r}$ & $\mathrm{N}$ & $\mathrm{r}$ & $\mathrm{N}$ & $\mathrm{r}$ & $\mathrm{N}$ & $\mathrm{r}$ & $\mathrm{N}$ \\
\hline Nurturance & .012 & 239 & .049 & 253 & .055 & 157 & .030 & 251 & .078 & 253 & $.257 * *$ & 253 \\
\hline $\begin{array}{l}\text { Instrumental } \\
\text { Involvement }\end{array}$ & .103 & 239 & $.142^{*}$ & 253 & .122 & 157 & .049 & 251 & $.189 *$ & 253 & $.272^{* *}$ & 253 \\
\hline $\begin{array}{l}\text { Expressive } \\
\text { Involvement }\end{array}$ & -.009 & 239 & .055 & 253 & $.167 *$ & 157 & .039 & 251 & $.161^{* *}$ & 253 & $.271^{* *}$ & 253 \\
\hline $\begin{array}{l}\text { Mentoring } \\
\text { Involvement }\end{array}$ & .078 & 238 & $.129 *$ & 252 & $.092 * *$ & * 156 & .052 & 250 & $.245^{* *}$ & 253 & $.276^{* *}$ & 252 \\
\hline $\begin{array}{l}\text { Desired } \\
\text { Instrumental }\end{array}$ & .062 & 114 & .042 & 122 & .130 & 122 & $.253^{* * *}$ & * 122 & $.170^{*}$ & 122 & $.150^{*}$ & 122 \\
\hline $\begin{array}{l}\text { Desired } \\
\text { Expressive }\end{array}$ & .005 & 149 & .042 & 158 & .168 & 92 & $.217^{*}$ & 156 & .080 & 158 & .046 & 158 \\
\hline
\end{tabular}


Table 25

\begin{tabular}{|c|c|c|c|c|c|c|c|c|c|c|c|c|}
\hline \multicolumn{13}{|c|}{ Impact of Mothering on Daughters from Divorced Families } \\
\hline \multirow{2}{*}{$\begin{array}{l}\text { Maternal } \\
\text { Parenting } \\
\text { variable }\end{array}$} & \multicolumn{2}{|c|}{ HS GPA } & \multicolumn{2}{|c|}{ HS Grade } & \multicolumn{2}{|c|}{$\begin{array}{l}\text { College } \\
\text { GPA }\end{array}$} & \multicolumn{2}{|c|}{$\begin{array}{l}\text { College } \\
\text { Grade }\end{array}$} & \multicolumn{2}{|c|}{ Satisfaction } & \multicolumn{2}{|c|}{ Importance } \\
\hline & $\mathrm{r}$ & $\mathrm{N}$ & $\mathrm{r}$ & $\mathrm{N}$ & $\mathrm{r}$ & $\mathrm{N}$ & $\mathrm{r}$ & $\mathrm{N}$ & r & $\mathrm{N}$ & $\mathrm{r}$ & $\mathrm{N}$ \\
\hline Nurturance & .016 & 312 & .082 & 325 & .009 & 225 & .029 & 320 & .007 & 325 & .076 & 325 \\
\hline $\begin{array}{l}\text { Instrumental } \\
\text { Involvement }\end{array}$ & -.001 & 313 & .037 & 326 & -.100 & 255 & -.043 & 322 & .018 & 326 & $.167^{* *}$ & 326 \\
\hline $\begin{array}{l}\text { Expressive } \\
\text { Involvement }\end{array}$ & .007 & 313 & .085 & 326 & .018 & 225 & .043 & 321 & .003 & 326 & $.112^{*}$ & 326 \\
\hline $\begin{array}{l}\text { Mentoring } \\
\text { Involvement }\end{array}$ & .017 & 312 & .041 & 325 & -.035 & 224 & -.008 & 321 & .038 & 325 & .190 & 325 \\
\hline $\begin{array}{l}\text { Desired } \\
\text { Instrumental }\end{array}$ & -.087 & 175 & -.054 & 182 & -.100 & 129 & -.104 & 180 & .006 & 182 & -.018 & 270 \\
\hline $\begin{array}{l}\text { Desired } \\
\text { Expressive }\end{array}$ & -.086 & 238 & -.009 & 247 & -.022 & 247 & -.018 & 242 & .041 & 247 & .038 & 247 \\
\hline
\end{tabular}

Table 26

\begin{tabular}{|c|c|c|c|c|c|c|c|c|c|c|c|c|}
\hline \multicolumn{13}{|c|}{ Impact of Mothering on Daughters from Intact Families } \\
\hline \multirow{2}{*}{$\begin{array}{l}\text { Maternal } \\
\text { Parenting } \\
\text { variable }\end{array}$} & \multicolumn{2}{|c|}{ HS GPA } & \multicolumn{2}{|c|}{ HS Grade } & \multicolumn{2}{|c|}{$\begin{array}{l}\text { College } \\
\text { GPA }\end{array}$} & \multicolumn{2}{|c|}{$\begin{array}{l}\text { College } \\
\text { Grade }\end{array}$} & \multicolumn{2}{|c|}{ Satisfaction } & \multicolumn{2}{|c|}{ Importance } \\
\hline & $r$ & $\mathrm{~N}$ & $r$ & $\mathrm{~N}$ & $r$ & $\mathrm{~N}$ & $r$ & $\mathrm{~N}$ & $r$ & $\mathrm{~N}$ & $r$ & $\mathrm{~N}$ \\
\hline Nurturance & $.125^{* *}$ & 751 & $.153^{* *}$ & 780 & $.104 *$ & 526 & $.081^{*}$ & 776 & $.186^{* *}$ & 783 & $.122 * *$ & 782 \\
\hline $\begin{array}{l}\text { Instrumental } \\
\text { Involvement }\end{array}$ & $.135^{* *}$ & 752 & $.127 * *$ & 781 & .005 & 528 & .007 & 776 & $.149 * *$ & 784 & $.146^{* *}$ & 783 \\
\hline $\begin{array}{l}\text { Expressive } \\
\text { Involvement }\end{array}$ & $.100 * *$ & 754 & .115 & 783 & .025 & 528 & .051 & 778 & $.155^{* *}$ & 786 & $.109 * *$ & 785 \\
\hline $\begin{array}{l}\text { Mentoring } \\
\text { Involvement }\end{array}$ & $.135^{* *}$ & 748 & $.155^{* *}$ & 777 & .605 & 525 & .040 & 774 & $.161^{* *}$ & 780 & .099* & 779 \\
\hline $\begin{array}{l}\text { Desired } \\
\text { Instrumental }\end{array}$ & -.058 & 357 & .027 & 372 & .007 & 246 & -.013 & 369 & .033 & 374 & .054 & 373 \\
\hline $\begin{array}{l}\text { Desired } \\
\text { Expressive }\end{array}$ & -.055 & 492 & -.006 & 509 & -.060 & 342 & -.016 & 506 & -.007 & 511 & -.055 & 492 \\
\hline
\end{tabular}


Table 27

\begin{tabular}{|c|c|c|c|c|c|c|c|c|c|c|c|c|}
\hline \multicolumn{13}{|c|}{ Impact of Fathering on Sons from Divorced Families } \\
\hline \multirow{2}{*}{$\begin{array}{l}\text { Maternal } \\
\text { Parenting } \\
\text { variable }\end{array}$} & \multicolumn{2}{|c|}{ HS GPA } & \multicolumn{2}{|c|}{ HS Grade } & \multicolumn{2}{|c|}{$\begin{array}{l}\text { College } \\
\text { GPA }\end{array}$} & \multicolumn{2}{|c|}{$\begin{array}{l}\text { College } \\
\text { Grade }\end{array}$} & \multicolumn{2}{|c|}{ Satisfaction } & \multicolumn{2}{|c|}{ Importance } \\
\hline & $\mathrm{r}$ & $\mathrm{N}$ & $\mathrm{r}$ & $\mathrm{N}$ & $\mathrm{r}$ & $\mathrm{N}$ & $\mathrm{r}$ & $\mathrm{N}$ & $\mathrm{r}$ & $\mathrm{N}$ & $\mathrm{r}$ & $\mathrm{N}$ \\
\hline Nurturance & -.018 & 106 & .059 & 110 & .120 & 65 & -.023 & 111 & -.080 & 111 & -.077 & 111 \\
\hline $\begin{array}{l}\text { Instrumental } \\
\text { Involvement }\end{array}$ & .045 & 106 & -.097 & 110 & .149 & 65 & .005 & 111 & -.081 & 111 & .021 & 111 \\
\hline $\begin{array}{l}\text { Expressive } \\
\text { Involvement }\end{array}$ & .079 & 105 & -.057 & 109 & .119 & 64 & .074 & 110 & -.055 & 110 & -018. & 110 \\
\hline $\begin{array}{l}\text { Mentoring } \\
\text { Involvement }\end{array}$ & -.017 & 106 & -.050 & 750 & .114 & 65 & .002 & 111 & -.078 & 111 & -.042 & 111 \\
\hline $\begin{array}{l}\text { Desired } \\
\text { Instrumental }\end{array}$ & -.155 & 90 & -.161 & 93 & -.065 & 57 & -.066 & 94 & -.153 & 94 & .072 & 94 \\
\hline $\begin{array}{l}\text { Desired } \\
\text { Expressive }\end{array}$ & -.159 & 97 & -.084 & 101 & -.182 & 63 & -.010 & 102 & -.146 & 102 & .098 & 102 \\
\hline
\end{tabular}

Table 28

\begin{tabular}{|c|c|c|c|c|c|c|c|c|c|c|c|c|}
\hline \multicolumn{13}{|c|}{ Impact of Fathering on Sons from Intact Families } \\
\hline \multirow{2}{*}{$\begin{array}{l}\text { Maternal } \\
\text { Parenting } \\
\text { variable }\end{array}$} & \multicolumn{2}{|c|}{ HS GPA } & \multicolumn{2}{|c|}{ HS Grade } & \multicolumn{2}{|c|}{$\begin{array}{l}\text { College } \\
\text { GPA }\end{array}$} & \multicolumn{2}{|c|}{$\begin{array}{l}\text { College } \\
\text { Grade }\end{array}$} & \multicolumn{2}{|c|}{ Satisfaction } & \multicolumn{2}{|c|}{ Importance } \\
\hline & $\mathrm{r}$ & $\mathrm{N}$ & $r$ & $\mathrm{~N}$ & $\mathrm{r}$ & $\mathrm{N}$ & $r$ & $\mathrm{~N}$ & r & $\mathrm{N}$ & r & $\mathrm{N}$ \\
\hline Nurturance & -.056 & 238 & .003 & 252 & .108 & 156 & .045 & 250 & $.142 *$ & 252 & $.216 * *$ & 252 \\
\hline $\begin{array}{l}\text { Instrumental } \\
\text { Involvement }\end{array}$ & -.029 & 239 & .018 & 253 & $.173^{*}$ & 157 & .088 & 251 & $.160 * *$ & 253 & $.230 * *$ & 253 \\
\hline $\begin{array}{l}\text { Expressive } \\
\text { Involvement }\end{array}$ & -.105 & 239 & -.009 & 253 & .124 & 157 & .088 & 251 & $.185^{* *}$ & 253 & $.228 * *$ & 253 \\
\hline $\begin{array}{l}\text { Mentoring } \\
\text { Involvement }\end{array}$ & -.077 & 237 & -.027 & 251 & .120 & 156 & .096 & 249 & $.110 *$ & 254 & $.206^{* *}$ & 251 \\
\hline $\begin{array}{l}\text { Desired } \\
\text { Instrumental }\end{array}$ & .016 & 189 & .043 & 201 & .089 & 126 & $.158^{*}$ & 199 & .032 & 201 & .028 & 201 \\
\hline $\begin{array}{l}\text { Desired } \\
\text { Expressive }\end{array}$ & .069 & 222 & . 106 & 234 & $.148^{*}$ & 146 & $.138^{*}$ & 232 & .071 & 234 & .015 & 234 \\
\hline
\end{tabular}


Table 29

\begin{tabular}{|c|c|c|c|c|c|c|c|c|c|c|c|c|}
\hline \multicolumn{13}{|c|}{ Impact of Fathering on Daughters from Divorced Families } \\
\hline \multirow{2}{*}{$\begin{array}{l}\text { Paternal } \\
\text { Parenting } \\
\text { variable }\end{array}$} & \multicolumn{2}{|c|}{ HS GPA } & \multicolumn{2}{|c|}{ HS Grade } & \multicolumn{2}{|c|}{$\begin{array}{l}\text { College } \\
\text { GPA }\end{array}$} & \multicolumn{2}{|c|}{$\begin{array}{l}\text { College } \\
\text { Grade }\end{array}$} & \multicolumn{2}{|c|}{ Satisfaction } & \multicolumn{2}{|c|}{ Importance } \\
\hline & $\mathrm{r}$ & $\mathrm{N}$ & $\mathrm{r}$ & $\mathrm{N}$ & $\mathrm{r}$ & $\mathrm{N}$ & $\mathrm{r}$ & $\mathrm{N}$ & $\mathrm{r}$ & $\mathrm{N}$ & $\mathrm{r}$ & $\mathrm{N}$ \\
\hline Nurturance & .013 & 305 & .021 & 317 & $.134^{*}$ & 222 & -.007 & 313 & .020 & 317 & .076 & 317 \\
\hline $\begin{array}{l}\text { Instrumental } \\
\text { Involvement }\end{array}$ & .025 & 309 & .056 & 321 & $.116^{*}$ & 224 & -.007 & 316 & .087 & 321 & .055 & 321 \\
\hline $\begin{array}{l}\text { Expressive } \\
\text { Involvement }\end{array}$ & .032 & 307 & .022 & 319 & .092 & 222 & -.012 & 315 & .041 & 319 & .048 & 319 \\
\hline $\begin{array}{l}\text { Mentoring } \\
\text { Involvement }\end{array}$ & -.017 & 106 & -.124 & 110 & .114 & 65 & .002 & 111 & .047 & 319 & .069 & 319 \\
\hline $\begin{array}{l}\text { Desired } \\
\text { Instrumental }\end{array}$ & -.031 & 264 & -.029 & 273 & -.055 & 188 & .001 & 270 & -.097 & 273 & -.034 & 273 \\
\hline $\begin{array}{l}\text { Desired } \\
\text { Expressive }\end{array}$ & -.064 & 287 & -.021 & 297 & .002 & 204 & -.067 & 293 & -.013 & 297 & -.023 & 297 \\
\hline
\end{tabular}

Table 30

\begin{tabular}{|c|c|c|c|c|c|c|c|c|c|c|c|c|}
\hline \multicolumn{13}{|c|}{ Impact of Fathering on Daughters from Intact Families } \\
\hline \multirow{2}{*}{$\begin{array}{l}\text { Paternal } \\
\text { Parenting } \\
\text { Variable }\end{array}$} & \multicolumn{2}{|c|}{ HS GPA } & \multicolumn{2}{|c|}{ HS Grade } & \multicolumn{2}{|c|}{$\begin{array}{l}\text { College } \\
\text { GPA }\end{array}$} & \multicolumn{2}{|l|}{$\begin{array}{l}\text { College } \\
\text { Grade }\end{array}$} & \multicolumn{2}{|c|}{ Satisfaction } & \multicolumn{2}{|c|}{ Importance } \\
\hline & $\mathrm{r}$ & $\mathrm{N}$ & $r$ & $\mathrm{~N}$ & $\mathrm{r}$ & $\mathrm{N}$ & $r$ & $\mathrm{~N}$ & $r$ & $\mathrm{~N}$ & $r$ & $\mathrm{~N}$ \\
\hline Nurturance & .058 & 751 & .082 & 780 & $.138 * *$ & 526 & $.086^{*}$ & 775 & $.146 * *$ & 783 & .056 & 786 \\
\hline $\begin{array}{l}\text { Instrumental } \\
\text { Involvement }\end{array}$ & .056 & 753 & $.115^{* *}$ & 782 & .015 & 528 & .010 & 777 & $.135^{* *}$ & 785 & $.117 * *$ & 784 \\
\hline $\begin{array}{l}\text { Expressive } \\
\text { Involvement }\end{array}$ & .046 & 749 & $.090 * *$ & 778 & .068 & 524 & .052 & 774 & $.184^{* *}$ & 781 & $.082 *$ & 780 \\
\hline $\begin{array}{l}\text { Mentoring } \\
\text { Involvement }\end{array}$ & .050 & 750 & $.119^{* *}$ & 779 & .057 & 779 & $.059^{*}$ & 775 & $.152^{* *}$ & 782 & $.088^{* *}$ & 781 \\
\hline $\begin{array}{l}\text { Desired } \\
\text { Instrumental }\end{array}$ & .016 & 189 & .043 & 243 & .089 & 186 & $.158^{*}$ & 199 & .032 & 201 & .028 & 598 \\
\hline $\begin{array}{l}\text { Desired } \\
\text { Expressive }\end{array}$ & -.030 & 710 & -.008 & 739 & -.051 & 497 & -.013 & 736 & -.034 & 741 & .019 & 741 \\
\hline
\end{tabular}


Effect Sizes for Nurturance, Reported Involvement, and Desired Involvement

Over 66 correlations were calculated testing the relationship between parenting variables and child academic outcomes differentiated by gender and family form. It is a risk that significant relationships will surface by chance when conducting large numbers of correlations.

Table 31

\begin{tabular}{|c|c|c|c|c|}
\hline $\begin{array}{l}\text { Effect } \\
\text { size }\end{array}$ & Parenting Variable & $\begin{array}{l}\text { Academic } \\
\text { Outcome }\end{array}$ & Family form & $\begin{array}{l}\text { Child } \\
\text { Gender }\end{array}$ \\
\hline .15 & Mother Desired Expressive & College GPA & Divorced & Male \\
\hline .14 & Mother Desired Instrumental & HS Grade & Divorced & Male \\
\hline .12 & Mother Desired Instrumental & Satisfaction & Divorced & Male \\
\hline .11 & Mother Desired Instrumental & HS GPA & Divorced & Male \\
\hline 11 & Mother Reported Instrumental & HS Grade & Divorced & Male \\
\hline 10 & Mother Nurturance & College GPA & Divorced & Male \\
\hline 10 & Mother Desired Expressive & Satisfaction & Divorced & Male \\
\hline .10 & Mother Desired Instrumental & College GPA & Divorced & Male \\
\hline .09 & Mother Desired Instrumental & Satisfaction & Divorced & Male \\
\hline .09 & Mother Desired Instrumental & HS Grade & Divorced & Male \\
\hline .08 & Mother Reported Instrumental & HS GPA & Divorced & Male \\
\hline .08 & Mother Reported Expressive & College GPA & Divorced & Male \\
\hline .08 & Mother Desired Instrumental & HS GPA & Divorced & Male \\
\hline .08 & Mother Desired Expressive & HS Grade & Divorced & Male \\
\hline .07 & Mother Nurturance & Satisfaction & Divorced & Male \\
\hline .07 & Mother Nurturance & Importance & Intact & Male \\
\hline .07 & Mother Reported Instrumental & Importance & Intact & Male \\
\hline .06 & Mother Reported Instrumental & Satisfaction & Intact & Male \\
\hline .06 & Mother Reported Expressive & HS GPA & Divorced & Male \\
\hline .06 & Mother Reported Expressive & Importance & Intact & Male \\
\hline .06 & Mother Desired Expressive & HS GPA & Divorced & Male \\
\hline .05 & Father Nurturance & Satisfaction & Intact & Male \\
\hline .05 & Father Reported Instrumental & Importance & Intact & Male \\
\hline .05 & Father Reported Expressive & Importance & Intact & Male \\
\hline
\end{tabular}

Because gender and family form subgroups varied greatly in size given sample size differences between intact $(n=1040)$ and divorced $(n=443)$ families, effect sizes were used to analyze the results, correcting for the subgroup size discrepancies. To ease 
interpretation of relevant findings, the effect sizes were rank ordered as displayed in Table 31.

The results of the rank ordering showed a continuous pattern of effect sizes, with every value being represented between .05 and .12 . Cohen's conventions about $r$ square designate values of .09 to .25 as a medium effect size. However, because of the patterning in the results, for the present study an effect size of .08 or greater was considered medium. Recent researchers have emphasized that effect size reporting standards are merely guidelines and that analytic decisions should be made with regard to the data set, data collection, methodology and implications for practical application and public policy (e.g. McCartney \& Rosenthal, 2000).

By establishing the $r$-square cutoff as .08, a practical benefit is gained such that all of the medium effect sizes are found in one subgroup, representing a clear and interpretable finding. The Pearson correlations and corresponding effect sizes revealed a moderately strong, positive correlation between the amount of maternal nurturance and maternal involvement, and the academic achievement of sons in divorced families. Similarly a moderately strong, negative correlation was found between desired mother involvement dimensions and academic outcomes for males from divorced families. Thus, the more nurturant and involved divorced mothers were with their sons, the higher their academic achievement. Sons from divorced families who reported that they wanted more involvement from their mother scored lower on the academic outcome measures. Unique Variance Explained (UVE) Analyses.

As a check on the results found in the correlational analyses, unique variance explained estimates (UVE's) were calculated for the nurturance and perceived 
involvement variables. The UVE's were calculated using stepwise multiple regression, by first entering one parenting variable (e.g. reported father instrumental involvement) and then entering the corresponding parenting variable for the other parent (e.g. reported mother instrumental involvement) and then examining $r$-square change statistics to assess the unique variance accounted for by the parent variable entered last. As the mother involvement scales and the father involvement scales were isomorphic, they could be entered into the stepwise multiple regression to assess UVE (Finley, Mira \& Schwartz, 2008).

Table 32

\begin{tabular}{|c|c|c|c|c|}
\hline \multicolumn{5}{|c|}{ Unique Variance Explained Analyses } \\
\hline Child & Family & Parenting Variable & Academic & UVE \\
\hline Gender & Form & & Outcome & \\
\hline Male & Divorced & Desired Mother Expressive & College GPA & $14.9 \%$ \\
\hline Male & Divorced & Mother Instrumental & HS Grade & $13.4 \%$ \\
\hline Male & Divorced & Mother Nurturance & College GPA & $10.6 \%$ \\
\hline Male & Divorced & Desired Mother Expressive & HS Grade & $10 \%$ \\
\hline Male & Divorced & Desired Mother Expressive & Satisfaction & $8.3 \%$ \\
\hline Male & Divorced & Desired Mother Instrumental & Satisfaction & $7.2 \%$ \\
\hline Male & Divorced & Mother Nurturance & Satisfaction & $7 \%$ \\
\hline Male & Divorced & Desired Mother Instrumental & HS Grade & $6.9 \%$ \\
\hline Male & Divorced & Desired Mother Instrumental & HS GPA & $5.6 \%$ \\
\hline Male & Divorced & Mother Expressive Involvement & HS GPA & $5.3 \%$ \\
\hline Male & Divorced & Desired Mother Expressive & HS GPA & $5.1 \%$ \\
\hline Male & Divorced & Desired Mother Instrumental & College Grade & $4.8 \%$ \\
\hline Male & Divorced & Mother Nurturance & HS Grade & $4 \%$ \\
\hline
\end{tabular}

The results of the UVE analyses were consistent with the findings from the correlational analyses, thus serving as an internal replication of the results. The higher percentages of unique variance found were accounted for by the variables that yielded the highest effect sizes. All of the UVE analyses that yielded a percentage of $4 \%$ or greater were for mothering variables positively affecting the academic outcomes of sons from 
divorced family forms. Although the percentages of UVE were relatively modest, they represented a consistent finding. Also, it would be expected that the percentages would be modest, given that academic outcomes are affected by a wide variety of variables outside of parent-child relationship histories. The results of the UVE are depicted in Table 32. 


\section{CHAPTER 6}

\section{DISCUSSION}

In the present study, the effects of dimensions of parenting on child academic outcomes were examined. A phenomenologically-based measure developed by Finley and Schwartz $(2004 ; 2008)$ was employed to assess retrospectively the childhood experiences of emergent adult college students regarding the nurturance and involvement of their mothers and their fathers. Students also reported several indicators of academic achievement and motivation. The results of the study affirm the conclusion that important and significant effects and relationships can be missed when the effects of dimensions of parenting are assessed without exploring unique processes and effects of mothering and fathering. Mothering and fathering have overlapping influences, but also provide unique and discrete contributions to child outcomes.

In addition to differential effects being identified for mothering and fathering, differential effects were found for sons and daughters from divorced versus intact families. Mother nurturance and involvement was found to significantly positively influence academic outcomes for sons from divorced families. Father nurturance did not influence academic outcomes for sons from divorced families. This finding of differential effects provides further support for the importance of analyzing mothering and fathering independently and exploring effects specific to child gender and family form.

In this discussion, the results obtained for the relations of mother and father nurturance and involvement to the academic outcome measures will be summarized and 
conclusions based on these results will be offered. Finally, limitations of the study will be discussed, along with suggestions for further research.

\section{Parental Nurturance}

Results obtained in this study confirm that parental nurturance is correlated with positive child academic outcomes. This finding is robust in the literature with parental nurturance positively impacting child academic outcomes across ethnicities, countries, age groups and studies utilizing different methodologies to collect and analyze data (Jeneyes, 2003; MacDonald, 1992; Sands \& Plunkett, 2005; Sandler et al., 2012; Venezaino, 2003).

The present study found that, in intact family forms, mother nurturance and father nurturance are significantly correlated with each other. This result is likely because in intact families, mothers and fathers collaborate in parenting and share common beliefs, goals and practices. Mother nurturance and father nurturance were also found to have a positive impact on the academic outcomes of young adult sons and daughters from intact families.

In divorced families, mother nurturance and father nurturance were not correlated. This suggests that in a divorce process impacts the family system and parenting variables are more disparate. This can create a "divided world” for children of divorce where they have to negotiate two households with unique and separate parenting styles (Amato, 1998; Marquedt, 2005; Schwartz \& Finley, 2010). Unique effects were found for mother nurturance and father nurturance on sons' and daughters' academic outcomes. Mother nurturance was found to have a strong, positive effect on son's academic outcomes including high school grades, college GPA and overall satisfaction with their academic 
performance. There was no relationship between mother nurturance and daughters' academic outcomes in divorced families. No relationship was identified between father nurturance and sons' academic outcomes in divorced families, but there was a single significant, yet weak, positive correlation between father nurturance and daughters’ college GPA.

These results demonstrate a possible cross-gender effect, suggesting that maternal nurturance is an important factor in the academic success of sons from divorced families and that father nurturance may be an important influence on the academic success of daughters from divorced families. Although the correlation between father nurturance and the college GPA of daughters from divorced families in the present study was weak and the finding must be interpreted with caution, it is consistent with other studies in the literature where father nurturance was found to have a positive effect on daughter's academic outcomes and career success across cultures and countries (Biller 1973; Deb \& Gulati 1989; Hunter 2003; King 1994; Lee, Kushner, \& Cho 1994; and Villegas 2006).

Thus, the present results, together with prior findings, suggest that the opposite sex parent's nurturance behavior may be important contributor to positive academic outcomes. Therefore, it is daughters' academic outcomes that may suffer if paternal nurturance is negatively affected through a divorce process. Similarly, maternal nurturance and maternal involvement may serve as a protective factor for academic success for sons from divorced family forms.

\section{Reported Parental Involvement}

In intact families, maternal involvement and paternal involvement both affected child academic outcomes positively. The correlations were weak to moderate, but there 
was consistency in the pattern of results suggesting a meaningful finding. In divorced families, the impact of fathering on sons appeared to drop out completely. The correlations between paternal involvement and academic outcomes for sons from divorced families did not yield any relationships of significance.

The correlations between paternal involvement and academic outcomes for daughters from divorced families yielded one significant relationship. However, this correlation between father instrumental involvement and college GPA for daughters from divorced families was small and must be interpreted with caution. Although there is support in the literature for the impact of father involvement on daughters' academic outcomes (Carlson, 2006; Liang, 2003; Stolz, Barber, \& Olsen, 2005; Sun \& Li, 2001), the findings from the present study are not definitive and warrant further examination in future research.

The strongest and most consistent finding in the involvement domains was the importance of maternal involvement on academic outcomes for sons from divorced families. Having an involved mother across involvement domains improved the entire range of academic achievement and motivation outcome indicators for sons from divorced families. Therefore, having an involved mother may serve as a protective factor for sons in the context of the stressor of divorce. An alternate explanation is that mothers may invest more in sons' academics with the absence of the father and the son may assume the gender roles of provider (Amato 1994, Mott, 1994; Umberson, 1992).

\section{Desired Parental Involvement}

The desired involvement variables were less than half of the involvement scale’s variables, but they constituted 5 out of the 7 highest effect sizes and thus 
disproportionately carried the effects. Again, the most pronounced effects were for the desired involvement of mothers for sons from divorced families. Sons who indicated that they desired more involvement than they perceived their mothers as having provided had less favorable academic outcomes

The significance of the desired involvement measure in this study provides support for the importance of continued research on this parenting domain through a phenomenological approach. Desired involvement is an interesting variable as it is not a measure of actual parental involvement behavior, but rather, how the level of parental involvement behavior fits the needs and desires of the child. The current results may serve to illustrate the importance of considering child perspectives when making decisions and rulings in child custody cases in the context of divorce (Barnett \& Wilson, 2004; Finley \& Schwartz, 2010; Marquardt, 2005). Indeed, the best interest of the child may be best ascertained by considering the child's perspective.

\section{Limitations and Future Directions}

One limitation of this research is that the sample for the study was predominately adult children from families of Hispanic descent. Thus, the findings may be, to some extent, culturally specific. Future research could examine the relation of parental nurturance and involvement to academic outcomes in a more ethnically diverse sample.

Also, because the participants in the study were all college students, the sample consisted of a restricted range of individuals who had overall positive academic outcomes. Thus the findings were clustered in the positive direction. If the sample had been more representative of the general population of emergent adults, it would have 
included individuals who had negative academic outcomes, such as dropping out of high school and exhibiting poor high school academic achievement.

Because the sample was comprised of individuals with relatively positive academic outcomes, it was not possible to assess the impact of parental nurturance on involvement on young adult children with negative academic outcomes. The absence of low achieving individuals in the sample may account, in part, for the modest effect sizes obtained in this study and for the relatively weak relationships found between fathering and academic outcomes. It would be beneficial for future research to analyze the relationships between parenting variables and child academic outcomes in a sample that is more representative of the general population, including individuals who have not experienced the success of advancing to college.

\section{General Conclusions}

Despite some limitations, the results of this study demonstrated a clear positive relationship between mothering and academic outcomes for sons from divorced families. The strongest correlations were all found for the subgroup of mothers and sons in divorced families, as well as the highest effect sizes and greatest percentages of unique variance explained. In this group, significant correlations were found between the academic outcome measures and mother nurturance, mother instrumental involvement, mother expressive involvement, mother mentoring involvement, desired mother instrumental involvement, and desired mother expressive involvement. These results suggest that mothering is especially important for academic outcomes for sons from divorced families. 
Overall the findings of this study suggest that, in intact families, both mothering and fathering are important for child academic outcomes, although the correlations relative to these results were relatively weak. In divorced families, as noted above, mothering variables were prominently related to sons’ academic success. However, given past research indicating the importance of fathers to the academic achievement of their offspring, the role of paternal nurturance and involvement may have been underestimated in this study. In general, the results may have been attenuated in the current sample of relatively high achieving students. Further research is needed with ethnically representative samples of emerging adults, including weak academic performers who do not attend college.

The present findings offer support for the use of the Nurturant Parenting Scales and Reported and Desired Parental Involvement Scales developed by Finley \& Schwartz (2004). These scales offer researchers a tool that can examine unique effects of mothering and fathering for both sons and daughters. An additional advantage of these scales is that they can be used for all family forms. As family structures continue to become increasingly diverse, it will become increasingly important to analyze parenting variables across family forms. 


\section{REFERENCES}

Amato, P. R. (1998). More than money? Men's contributions to their children's lives. (pp. 241-278) Lawrence Erlbaum Associates Publishers, Mahwah, NJ.

Amato, P. R. (1994). Father-child relations, mother-child relations and offspring psychological well-being in adulthood. Journal of Marriage and the Family, 56, 1031-1042.

Amato P and Gilbreth J (1999). Nonresident fathers and children's wellbeing: a meta-. Analysis. Journal of Marriage and the Family, 61,557-573.

Bahal, M. \& Sexena, V. (1978). Effects of family setting upon cognitive development of the children: A review. Child Psychiatry Quarterly; 11, 1, 1-5.

Barber, N. (1998). Sex differences in disposition towards kin, security of adult attachment, and sociosexuality as a function of parental divorce. Evolution and Human Behavior, 19(2), 125-132.

Barnett, C., \& Wilson, J. C. (2004). Children's "wishes" in the australian family court: Are they wishful thinking? Psychiatry, Psychology and Law, 11(1), 73-78. doi:http://dx.doi.org/10.1375/1321871041335939

Bean, R. A., Bush, K. R., McKenry, P. C., \& Wilson, S. M. (2003). The impact of parental support, behavioral control, and psychological control on the academic achievement and self-esteem of african american and european american adolescents. Journal of Adolescent Research, 18(5), 523-541.

Bertram, A. N. (2006). The relationship of parent involvement and post-divorce adjustment to the academic achievement and achievement motivation of school-aged children. (Order No. AAI3202872, Oklahoma State University). Dissertation Abstracts International Section A: Humanities and Social Sciences, 4295.

Beyer, S. (1995). Maternal employment and children's academic achievement: Parenting styles as mediating variable. Developmental Review, 15(2), 212-253.

Boney, V. M. (2002). Predictors of cognitive hardiness in young adult children of divorce. (Order No. 3083970, University of Florida). ProQuest Dissertations and Theses,165-165.

Bronte-Tinkew, J., Moore, K. A., Capps, R. C., \& Zaff, J. (2006). The influence of father involvement on youth risk behaviors among adolescents: A comparison of nativeborn and immigrant families. Social Science Research, 35(1), 181-209. doi:http://dx.doi.org/10.1016/j.ssresearch.2004.08.002 
Cabrera, N. J. (2010). Father involvement and public policies. The role of the father in child development (5th ed.). (pp. 517-550) John Wiley \& Sons Inc, Hoboken, NJ.

Carlson, M.J. (2006). Family structure, father involvement, and adolescent behavioral outcomes. Journal of Marriage and Family, 68, 137-154.

Casanova, P.F., Garcia-Linares, M. C., Manuel, J., \& Carpio, M. (2005). Influence of family and socio-demographic variables on students with low academic achievement. Educational Psychology, 25(4), 423-435.

Chen, X., Rubin, K. H., \& Li, D. (1997). Relation between academic achievement and social adjustment: Evidence from chinese children. Developmental Psychology, 33(3), 518-525. doi:http://dx.doi.org/10.1037/0012-1649.33.3.518

Coley, R. L. (1998). Children's socialization experiences and functioning in singlemother households: The importance of fathers and other men. Child Development, 69(1), 219-230.

Coltrane, S., \& Behnke, A. (2013). Fatherhood and family policies Routledge/Taylor \& Francis Group, New York, NY.

Dornbusch, S. M., Ritter, P. L., Leiderman, P. H., Roberts, D. F., \& Fraleigh, M. J. 1987 The relation of parenting style to adolescent school performance. Child Development 58: 1244-1257.

DuBois, D. L., Felner, R. D., Meares, H., \& Krier, M. (1994). Prospective investigation of the effects of socioeconomic disadvantage, life stress, and social support on early adolescent adjustment. Journal of Abnormal Psychology, 103(3), 511-522. doi:http://dx.doi.org/10.1037/0021-843X.103.3.511

Fan, X. \& Chen, M. (2001). Parental Involvement and Students’ Academic Achievement: A Meta-Analysis. Educational Psychology Review, 13, 1, 1-22.

Finley, G.E. (2002). The best interest of the child and the eye of the beholder. [Re Review of C. Panter-Brick \& M. T. Smith (Eds.) Abandoned Children].

Finley, G. E., Mira, S. D., \& Schwartz, S. J. (2008). Perceived paternal and maternal involvement: Factor structures, mean differences, and parental roles. Fathering, 6(1), 62-82.

Finley, G. E., \& Schwartz, S. J. (2010). The divided world of the child: Divorce and longterm psychosocial adjustment. Family Court Review, 48(3), 516-527. doi:http://dx.doi.org/10.1111/j.1744-1617.2010.01326.x 
Finley, G.E. \& Schwartz, S.J. (2007). Father involvement and long-term young adult outcomes: The differential contributions of divorce and gender. Family Court Review, 45, 4, 573-587.

Finley, G.E. \& Schwartz, S.J. (2006). Parsons and Bales Revisited: Young Adult Children's Characterization of the Fathering Role. Psychology of Men and Masculinity, 7(1), 42-55.

Finley, G. E., \& Schwartz, S. J. (2004). The father involvement and nurturant fathering scales: Retrospective measures for adolescent and adult children. Educational and Psychological Measurement, 64(1), 143-164.

Finn, A. (1979). Academic success or failure: A clinical approach through open interviews with adolescents and their parents. Revue de Psychologie Appliquée, 29, 1, 1-14.

Fitzpatrick, J. W. (2014). Effects of a technology-based parental-involvement program on student achievement in mathematics.(Order No. AAI3565652, Dissertation Abstracts International Section A: Humanities and Social Sciences.

Glasgow, K. L., Dornbusch, S. M., Troyer, L., Steinberg, L., \& Ritter, P. L. (1997). Parenting styles, adolescents' attributions, and educational outcomes in nine heterogeneous high schools. Child Development, 68, 507-529.

Gonzalez-dehass, A., Willems, P. P., Holbein, M. F., \& Doan. (2005). Examining the relationship between parental involvement and student motivation. Educational Psychology Review, 17(2), 99-123. doi:http://dx.doi.org/10.1007/s10648-0053949-7

Gray, M.R. \& Steinberg, L. (1999). Unpacking Authoritative Parenting: Reassessing a Multidimensional Construct. Journal of Marriage and Family, 61,3, 574-587.

Grolnick, W. S., \& Slowiaczek, M. L. (1994). Parents' involvement in children's schooling: A multidimensional conceptualization and motivational model. Child Development, 65(1), 237-252.

Hawkins, A.J. \& Palkovitz, R. (1999). Beyond ticks and clicks: The need for more diverse and broader conceptualizations and measures of father involvement. The Journal of Men's Studies, 8, 1, 11-32.

Heard, H. E. (2007). Fathers, mothers, and family structure: Family trajectories, parent gender, and adolescent schooling. Journal of Marriage and Family, 69(2), 435450. 
Henry, C., Plunkett, S., \& Sands, T. (2011). Family structure, parental involvement, and academic motivation in latino adolescents. Journal of Divorce \& Remarriage, 52(6), 370-390. doi:http://dx.doi.org/10.1080/10502556.2011.592414

Hickman, C. W., Greenwood, G., \& Miller, M. D. 1995 High school parent involvement: Relationships with achievement, grade level, SES, and gender. Journal of Research and Development in Education 28: 125-134.

Hofferth, S. L., Pleck, J. H., Goldscheider, F., Curtin, S., \& Hrapczynski, K. (2013). Family structure and men's motivation for parenthood in the united states Routledge/Taylor \& Francis Group, New York, NY.

Holden, G. W., \& Edwards, L. A. (1989). Parental attitudes toward child rearing: Instruments, issues, and implications.Psychological Bulletin, 106(1), 29-58. doi:http://dx.doi.org/10.1037/0033-2909.106.1.29

Hong, S. \& Ho, H. (2005). Direct and Indirect Effects of Parental Involvement on Student Achievement: Second-Order Latent Growth Modeling Across Ethnic Groups. Journal of Educational Psychology, 97, 1, 32-42.

Hunter, M. H. (2003). Paternal influence on the development of comptencies that facilitate academic and occupational success in women. (Order No.

AAI3075424, Dissertation Abstracts International: Section B: The Sciences and Engineering, 6142.

Jenkins, J. M. (2013). Bringing leisure in: The benefits and importance of leisure to nonresident fatherhood and parent-child contact. Positive leisure science: From subjective experience to social contexts. (pp. 175-191) Springer Science + Business Media, New York, NY.

Jeynes, W. H. (2007). The relationship between parental involvement and urban secondary school student academic achievement: A meta-analysis. Urban Education, 42(1), 82-110. doi:http://dx.doi.org/10.1177/0042085906293818

Jeynes, W.H. (2003). A Meta-Analysis: The Effects of Parental Involvement on Minority Children's Academic Achievement. Education and Urban Society, 35, 2, 202-218.

Jeynes, W. H. (2002). Does parental involvement eliminate the effects of parental divorce on the academic achievement of adolescents? Journal of Divorce \& Remarriage, 37(1-2), 101-115. doi:http://dx.doi.org/10.1300/J087v37n01_06 
Kelly, J. B., \& Emery, R. E. (2003). Children's adjustment following divorce: Risk and resilience perspectives. Family Relations: An Interdisciplinary Journal of Applied Family Studies, 52(4), 352-362.

Khaleque, A. \& Rohner, R.P. (2002). Perceived Parental Acceptance-Rejection and Psychological Adjustment: A Meta-Analysis of Cross-Cultural and Intracultural Studies. Journal of Marriage and Family, 64, 54-64.

Kim, K. (1999). Parental warmth, control, and involvement in schooling in relation to Korean American adolescents' academic achievement. Dissertation Abstracts International Section A: Humanities and Social Sciences; 60(2-A); p. 0559.

Krampe, E. M., \& Newton, R. R. (2012). Reflecting on the father: Childhood family structure and women's paternal relationships. Journal of Family Issues, 33(6), 773-800. doi:http://dx.doi.org/10.1177/0192513X11425778

Lakshmi, A.R., \& Arora, M. (2006). Perceived parental behaviour as related to students' academic school success and competence. Journal of the Indian Academy of Applied Psychology, 32(1), 47-53.

Lamb, M.E. (1986). The emergent American father. In Lamb, M.E. (Ed.). The Father's Role: Applied Perspectives. Wiley, New York, pp3-25.

Lansford, J. E., Malone, P. S., Castellino, D. R., Dodge, K. A., Pettit, G. S., \& Bates, J. E. (2006). Trajectories of internalizing, externalizing, and grades for children who have and have not experienced their parents' divorce or separation. Journal of Family Psychology, 20(2), 292-301. doi:http://dx.doi.org/10.1037/08933200.20.2.292

Lau, Y. K. (2006). Nonresidential fathering and nonresidential mothering in a chinese context. American Journal of Family Therapy, 34(4), 373-394. doi:http://dx.doi.org/10.1080/01926180600553894

Lee, J., Chyung, Y.-J., \& Rohner, R. P. (1998). Relations among parental acceptancerejection, intimate partner acceptance-rejection, and psychological adjustment in Korean adults.

Locke, L. M., \& Prinz, R. J. (2002). Measurement of parental discipline and nurturance. Clinical Psychology Review, 22(6), 895-930. doi:http://dx.doi.org/10.1016/S0272-7358(02)00133-2

MacDonald, K. (1992). Warmth as a developmental construct: An evolutionary analysis. Child Development, 63, 753-733. 
Marjoribanks, K., \& Mboya, M. (1997). Family environmental correlates of students' affective characteristics: A south african study. Educational Studies, 23(2), 243252.

Marquardt, E. (2005, Nov 15). The children left behind; A pioneering study finds that loneliness and inner conflict are part of the legacy of divorce, no matter how amicable the split. Los Angeles Times

Martinez, C. R., Jr., DeGarmo, D. S., \& Eddy, J. M. (2004). Promoting academic success among latino youths. Hispanic Journal of Behavioral Sciences, 26(2), 128-151. doi:http://dx.doi.org/10.1177/0739986304264573

Martinez, C. R., \& Forgatch, M. S. (2002). Adjusting to change: Linking family structure transitions with parenting and boys' adjustment. Journal of Family Psychology : JFP : Journal of the Division of Family Psychology of the American Psychological Association (Division 43), 16(2), 107-117.

Mau, W. (1997). Parental influences on the high school students' academic achievement: A comparison of asian immigrants, asian americans, and white americans. Psychology in the Schools, 34(3), 267-277.

Mazur, E. (1993). Mother-Child communication and acceptance moderated relations between children's appraisals and their adjustment to parental divorce. Paper presented at the annual convention of the American Psychological Society, Chicago, IL.

Melby, J.N., \& Conger, R.D. (1996). Parental behaviors and adolescent academic performance: A longitudinal analysis. Journal of Research on Adolescence, 6, $113-137$.

McLanahan, S. S. (1999). Father absence and the welfare of children. (pp. 117-145). Mahwah, NJ, US: Lawrence Erlbaum Associates Publishers, Mahwah, NJ.

Mira, S. (2006). Development of the mother nurturance and mother involvement scales. Unpublished Maseter’s Theisis, Florida International University.

Mott, F.L. (1994). Sons, daughters, and father's absence: Differentials in father-leaving probabilities and in home environments. Journal of Family Issues, 5, 97-128.

Nielsen, L. (1999). College aged students of divorced parents: Facts and fiction. College Student Journal, 33(4), 543-572.

Palmer, D.L. (2004). The structure of maternal and paternal involvement in adolescence and relations to academic achievement. Dissertation Abstracts International: Section B: The Sciences and Engineering, 65(3-B); p. 1580. 
Parke, R.D. (2002). Fathers and families, In Bornstein, M.H. (ed.), Handbook of Parenting, Vol 3: Being and Becoming a Parent, Lawerence Erlbaum Associates, New Jersey, pp. 27-73.

Parker, G. and Barnett, B. (1988). Perception of parenting in childhood and social support in adulthood. American Journal of Psychiatry, 145, 479-482.

Parmar, P. \& Rohner, R. P. (2004). Relations between teachers' and parents’ warmth and behavioral control, and youths’ psychological adjustment, school conduct, and academic performance in India.

Paulson, S.E. (1994). Relations of parenting style and parental involvement with ninthgrade students' achievement. Journal of Early Adolescence, 14(2); p. 250-267.

Pettit, G.S., Bates, J.E., \& Dodge, K.A. (1997). Supportive parenting, ecological context, and children's adjustment: A seven-year longitudinal study. Child Development, 68, 908-923.

Plunkett, S. W., \& Bámaca-Gómez, M. Y. (2003). The relationship between parenting, acculturation, and adolescent academics in mexican-origin immigrant families in los angeles. Hispanic Journal of Behavioral Sciences, 25(2), 222-239. doi:http://dx.doi.org/10.1177/0739986303025002005

Popenoe, D. (1996). Life Without Father. New York: Free Press.

Pruett, M. K., Cowan, C. P., Cowan, P. A., \& Diamond, J. S. (2012). Supporting father involvement in the context of separation and divorce. Parenting plan evaluations: Applied research for the family court. (pp. 123-151) Oxford University Press, New York, NY.

Ranschburg, J., \& Bolla, I. K. (1985). Soziale lage und erziehungshaltung der eltern (untersuchung mit einer skala der erziehungshaltung). Zeitschrift Für Psychologie Mit Zeitschrift Für Angewandte Psychologie, 193(4), 415-430.

Rohner, R. P. (1986). The warmth dimension: Foundations of parental acceptancerejection theory. Beverly Hills, CA: Sage Publications, Inc.

Rohner, R. P., \& Britner, P. A. (2002). Worldwide mental health correlates of parental acceptance-rejection: Review of cross-cultural and intracultural evidence. CrossCultural Research: The Journal of Comparative Social Science, 36(1), 15-47. doi:http://dx.doi.org/10.1177/106939702129146316 
Rohner, R. P., Khaleque, A., \& Cournoyer, D. E. (2005). Cross-national perspectives on parental acceptance-rejection theory. Parent-youth relations: Cultural and crosscultural perspectives. (pp. 79-98) Haworth Press, New York, NY.

Rohner, R.P. \& Veneziano, R.A. (2001). The importance of father love: History and contemporary evidence, Review of General Psychology, 5.4, 382-405.

Ross, L. T., \& McDuff, J. A. (2008). The retrospective family unpredictability scale: Reliability and validity. Journal of Child and Family Studies, 17(1), 13-27. doi:http://dx.doi.org/10.1007/s10826-007-9138-1

Sandler, I., Wolchik, S., Winslow, E. B., Mahrer, N. E., Moran, J. A., \& Weinstock, D. (2012). Quality of maternal and paternal parenting following separation and divorce. Parenting plan evaluations: Applied research for the family court. (pp. 85-122) Oxford University Press, New York, NY.

Sands, T., \& Plunkett, S. W. (2005). A new scale to measure adolescent reports of academic support by mothers, fathers, teachers, and friends in latino immigrant families. Hispanic Journal of Behavioral Sciences, 27(2), 244-253. doi:http://dx.doi.org/10.1177/0739986304273968

Scaramella, L.V., Conger, R.D., Simons, R.L., \& Whitbeck, L.B. (1998). Predicting risk for pregnancy by late adolescence: A social contextual perspective. Developmental Psychology, 34(6), pp. 1233-1245.

Schwartz, S. J., \& Finley, G. E. (2010). Troubled ruminations about parents: Conceptualization and validation with emerging adults. Journal of Counseling and Development : JCD, 88(1), 80-91.

Schwartz, S. J., \& Finley, G. E. (2009). Mothering, fathering, and divorce: The influence of divorce on reports of and desires for maternal and paternal involvement. Family Court Review, 47(3), 506-522. doi:http://dx.doi.org/10.1111/j.1744-1617.2009.01270.x

Schwartz, S. J., Zamboanga, B. L., Ravert, R. D., Kim, S. Y., Weisskirch, R. S., Williams, M. K., ... Finley, G. E. (2009). Perceived parental relationships and health-risk behaviors in college-attending emerging adults. Journal of Marriage and Family, 71(3), 727-740. doi:http://dx.doi.org/10.1111/j.17413737.2009.00629.x

Schwartz, S.J. \& Finley, G.E. (2005). Fathering in Intact and Divorced Families: Ethnic Differences in Retrospective Reports. Journal of Marriage and Family, 67, 207215. 
Scott, M. E., Peterson, K., Ikramullah, E., \& Manlove, J. (2013). Multiple partner fertility among unmarried nonresident fathersRoutledge/Taylor \& Francis Group, New York, NY.

Scott , W.A.\& Scott, R. (1989). Family correlates of high-school student adjustment: A cross-cultural study. Australian Journal of Psychology, 41, 3, 269-284.

Simpkins, S.D. (2006). Mother-child relationship as a moderator of the relation between family educational involvement and child achievement. Parenting: Science and Practice, 6(1), 49-57.

Stevenson, M. M., Braver, S. L., Ellman, I. M., \& Votruba, A. M. (2013). Fathers, divorce, and child custody Routledge/Taylor \& Francis Group, New York, NY.

Steinberg, L., Elmen, J. D., \& Mounts, N. S. (1989). Authoritative parenting, psychosocial maturity, and academic success among adolescents. Child Development, 60(6), 1424-1436.

Steinberg, L., Lamborn, S. D., Dornbusch, S. M., \& Darling, N. (1992). Impact of parenting practices on adolescent achievement: Authoritative parenting, school involvement, and encouragement to succeed. Child Development 63: 1266-1281.

Stolz, H.E., Barber, B.K. \& Olsen, J.A. (2005). Toward Disentangling Fathering and Mothering: An Assessment of Relative Importance. Journal of Marriage and Family, 67, 1076-1092.

Sun, Y., \& Li, Y. (2001). Marital disruption, parental investment, and children's academic achievement: A prospective analysis. Journal of Family Issues, 22(1), 27-62.

Sun, Y., \& Li, Y. (2002). Children's well-being during parents' marital disruption process: A pooled time-series analysis. Journal of Marriage and Family, 64(2), 472-488.

Swan, D. W. (1996). Influence of father absence and satisfaction with parents on selected measures of nurturant fathering.(Order No. AAM9625086), Dissertation Abstracts International: Section B: The Sciences and Engineering, 2183.

Taylor, L. C.; Hinton, I.D. \& Wilson, M. N (1995). Parental influences on academic performance in African-American students. Journal of Child and Family Studies, 4, 3, 293 - 302. 
Trama, S. (2002). A study of academic achievement in relation to intelligence, parental involvement, and children's motivational resources: Control understanding, perceived competence, and self-regulation at upper elementary and secondary school levels. Dissertation Abstracts International: Section B: The Sciences and Engineering, 62(10-B); p. 4822.

Umberson, D. (1992). Relationships between adult children and their parents:

Psychological consequences for both generations. Journal of Marriage and the Family, 54(3), 664.

Varan, A. (2005). Relation between perceived parental acceptance and intimate partner acceptance in Turkey: Does history repeat itself? Ethos, 33, 414-426.

Vazsonyi, A.T. (2003). Parent-adolescent relations and problem behaviors: Hungary, the Netherlands, Switzerland, and the United States. Marriage and Family Review, 161-187.

Veneziano, R.A. (2003). The Importance of Paternal Warmth. Cross-Cultural Research, 37(3), 265-281.

Villegas, R. (2006). The relationship between quality of paternal relationship and paternal physical proximity and women's romantic attachments and sexuality. (Order No. AAI3221035, Dissertation Abstracts International: Section B: The Sciences and Engineering, , 3470.

Wagner, B. M., \& Phillips, D. A. (1992). Beyond beliefs: Parent and child behaviors and children's perceived academic competence. Child Development, 63(6), 13801391.

Williams, S.M., \& Finley, G.E. (1997). Father contact and perceived affective quality of fathering in Trinidad. Interamerican Journal of Psychology, 31, 315-319.

Williams, S. K., \& Kelly, F. D. (2005). Relationships among involvement, attachment, and behavioral problems in adolescence: Examining father's influence. The Journal of Early Adolescence, 25(2), 168-196. doi:http://dx.doi.org/10.1177/0272431604274178

Zill, N., Morrison, D. R., \& Coiro, M. J. (1993). Long-term effects of parental divorce on parent-child relationships, adjustment, and achievement in young adulthood. Journal of Family Psychology, 7(1), 91-103. doi:http://dx.doi.org/10.1037/0893-3200.7.1.91 


\section{Appendix \\ Complete Study Questionnaire}

\section{FATHER QUESTIONNAIRE}

This short, anonymous questionnaire will help us to understand how college students feel about their fathers. Please complete the entire questionnaire. Basically, we want to know how you felt about your father when you were growing up during childhood and adolescence.

Today, some children grow up with the same father throughout their lives while others have more than one father. If you had only one father, the choice below is simple. However, if you had more than one father, please answer the questionnaire for the father who had the most influence on you during childhood and/or adolescence. Please check the box below for the father you will be completing the questionnaire for.

biological father
adoptive father
stepfather
adoptive stepfather
other father figure (please specify)

Please answer the following questions from your perspective as a young adult (considering both childhood and adolescence) unless a particular age is specified in the question. Please answer for the father checked above.

1. How much do you think your father enjoyed being a father?

$$
\begin{aligned}
& \text { a great deal } \\
& \text { very much } \\
& \text { somewhat } \\
& \text { a little } \\
& \text { not at all }
\end{aligned}
$$

2. When you needed your father's support, was he there for you?

always there for me

often there for me

sometimes there for me

rarely there for me

never there for me

3. Did your father have enough

energy to meet your needs?

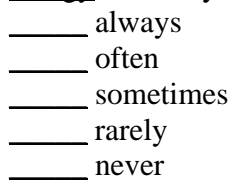

4. Did you feel that you could confide in (talk about important personal things with) your father? always

often

sometimes

rarely

never
5. Was your father available to spend time with you in activities?

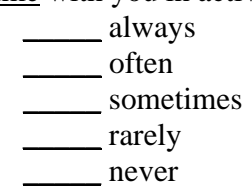

6. How emotionally close were you to your father? extremely close

very close somewhat close a little close not at all close

7. When you were an adolescent (teenager), how well did you get along with your father? very well well ok poorly very poorly

8. Overall, how would you rate your father? outstanding very good good fair poor

9. As you go through your day, does your father influence your daily thoughts and feelings?

always

often

sometimes

rarely

never 


\section{FATHER INVOLVEMENT IN CHILDHOOD AND ADOLESCENCE}

How involved was your father in the following aspects of your life and development?

Please place the appropriate number on the line before each of the following items.

5. always involved

4. often involved

3. sometimes involved

2. rarely involved

1. never involved

intellectual development

What did you want your father's level of involvement to be compared to what it actually was?

Please place the appropriate number on the line after each of the following items.

5. much more involved

4. a little more involved

3. it was just right

2. a little less involved

1. much less involved

10. emotional development

11. social development

12. ethical/moral development

14. spiritual development

15. physical development

16. career development

17. developing responsibility

18. developing independence

19. ___ developing competence

20. ___ leisure/fun/play

21. ___ providing income

22. ___ sharing activities/interests

23. ___ mentoring/teaching

24. caregiving

25. __ being protective

26. advising

27. discipline

28. school/homework

29. companionship 


\section{MOTHER QUESTIONNAIRE}

This short, anonymous questionnaire will help us to understand how college students feel about their mothers. Please complete the entire questionnaire. Basically, we want to know how you felt about your mother when you were growing up during childhood and adolescence.

Today, some children grow up with the same mother throughout their lives while others have more than one mother. If you had only one mother, the choice below is simple. However, if you had more than one mother, please answer the questionnaire for the mother who had the most influence on you during childhood and/or adolescence. Please check the box below for the mother you will be completing the questionnaire for.

biological mother

adoptive mother

stepmother

adoptive stepmother

other mother figure (please specify)

Please answer the following questions from your perspective as a young adult (considering both childhood and adolescence) unless a particular age is specified in the question. Please answer for the mother checked above.

1. How much do you think your mother enjoyed being a mother?

$\longleftarrow$ very much
somewhat
a gomeat deal
a little
not at all

2. When you needed your mother's support, was she there for you? always there for me

often there for me sometimes there for me rarely there for me never there for me

3. Did your mother have enough energy to meet your needs?

$$
\begin{aligned}
& \hline \text { always } \\
& \text { often } \\
& \text { sometimes } \\
& \text { rarely } \\
& \text { never }
\end{aligned}
$$

4. Did you feel that you could confide in (talk about important personal things with) your mother?

$$
\text { always }
$$

often

sometimes
rarely

never
5. Was your mother available to spend time with you in activities?

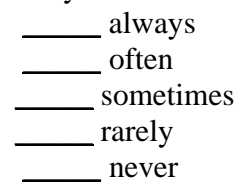

6. How emotionally close were you to your mother?

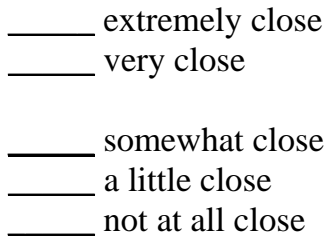

7. When you were an adolescent (teenager), how well did you get along with your mother?

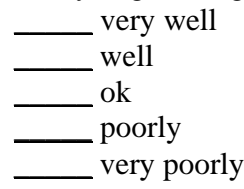

8. Overall, how would you rate your mother?

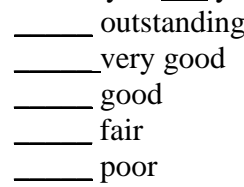

9. As you go through your day, does your mother influence your daily thoughts and feelings?

always

often

sometimes

rarely

never 


\section{MOTHER INVOLVEMENT IN CHILDHOOD AND ADOLESCENCE}

How involved was your mother in the following aspects of your life and development?

Please place the appropriate number on the line before each of the following items.

5. always involved

4. often involved

3. sometimes involved

2. rarely involved

1. never involved
What did you want your mother's level of involvement to be compared to what it actually was?

Please place the appropriate number on the line after each of the following items.

5. much more involved

4. a little more involved

3. it was just right

2. a little less involved

1. much less involved

10. intellectual development

11. emotional development

12. social development

13. ethical/moral development

14. spiritual development

15. physical development

16. career development

17. developing responsibility

18. ___ developing independence

19. ___ developing competence

20. ___ leisure/fun/play

21. ___ providing income

22. ___ sharing activities/interests

23. ___ mentoring/teaching

24. ___ caregiving

25.___ being protective

26. ___ advising

27. ___ discipline

28. __ school/homework 


\section{SELF QUESTIONNAIRE}

Directions: The questionnaire will now focus on questions about you. Where questions refer to "mother" and "father," please respond for the mother and father you completed the questionnaire for.

Again, we are now shifting from your mother/father to yourself, how would you describe your:

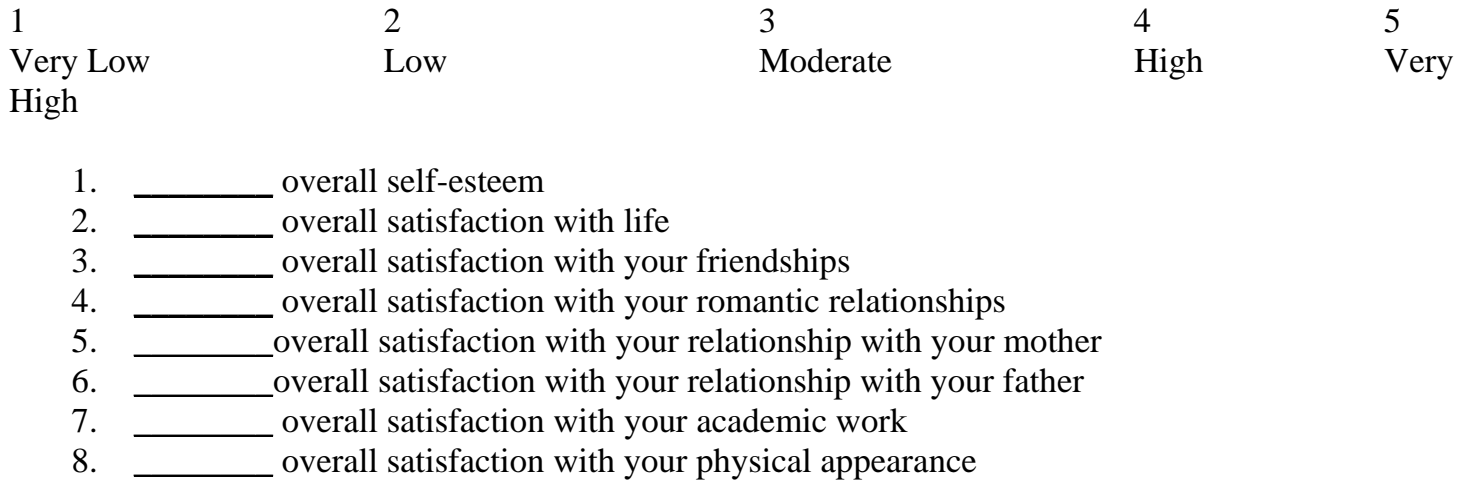

How important are the following in your life:

Not at all Important

2

Somewhat Important

Important
3

Important

4

Extremely

9. Academics

10. Friendships

11. Romantic Relationships

12. $\longleftarrow$ Family

13. $\longrightarrow$ Religion/Spiritual Beliefs

14. Sports/Physical Exercise

1

Completely False
2

Somewhat True
3

Mostly True
4

Completely True
15.

16.

17.

18.

19.

20.

21.

22.

23.

24.

25.

26.

27.

28.

29.

30.

In life, I have very clear goals and aims for myself.

I have discovered clear-cut goals and a satisfying life purpose.

There are lots of things about myself that I would change if I could. I have a low opinion of myself.

I often can't relax or calm down.

I often feel scared.

I often feel nervous and uncomfortable around people.

I often worry.

I feel sad a lot.

I frequently have trouble sleeping.

I find it hard to get started doing things.

I often feel that life is not worth living.

I often feel worthless.

I have frequent ups and downs in my mood.

I easily fall apart under stress.

I often get easily upset. 
1

Strongly Disagree
2

Disagree
3

Agree
4

Strongly Agree
5

Does Not Apply

31.

If my closest friend and I have a fight or argument, we can apologize and everything will be OK.

32. _ _ I can be completely open with my closest friend.

33. I I can always count on my closest friend.

34. $\longrightarrow$ My romantic partner(s) generally meet my emotional needs.

35. — I often wish I hadn't gotten into most of my romantic relationship(s).

36. I have a lot of problems in my romantic relationship(s).

1

23

34

Disagree Agree Strongly Agree

37.

I get taken advantage of in my romantic relationship(s).

38. My romantic relationship(s) have not lasted very long.

39. — My father caused most of the pain in my family.

40. I I wish my father had spent more time with me when I was younger.

41. There have been times when I wondered if my father even loved me.

42. _ I I feel that my father wanted to spend more time with me.

43. — My mother caused most of the pain in my family.

44. I I wish my mother had spent more time with me when I was younger.

45. There have been times when I wondered if my mother even loved me.

46. _ I I feel that my mother wanted to spend more time with me.

47. _ A lot of my parents' problems were because of me.

\section{BACKGROUND INFORMATION}

Please circle the appropriate answers below and fill in the relevant information.

1. Sex: Male Female

2. Current age:

3. Where do you live now?

With both parents With my Mother Other (please specify)

With my Father

On Campus

4. What is your current level? FR SO JR SR Other (please specify)

5. High School GPA:

6. College GPA (if applicable):

7. In college, I am (or expect to be) mostly: an "A" student $\quad$ a "B" student $\quad \mathrm{a}$ "C $\mathrm{C}$ " student $\quad \mathrm{a}$ " $\mathrm{D}$ " student

8. In high school, mostly I was: an "A" student $\quad$ a "B" student $\quad$ a "C" student $\quad$ a "D" student

9. What is your Race/Ethnicity? American Indian or Native Alaskan Asian or Pacific Islander

Black (Not of Hispanic Origin) Hispanic White (Not of Hispanic Origin)

10. Were you born in the United States? Yes No

If no, where were you born?

11. Was your father born in the United States? Yes No

If no, where was he born?

12. Was your mother born in the United States? Yes No

If no, where was she born? 
13. What was the highest level of education that your father completed?

Some High School or less High School Graduate Some College/Vocational College Graduate

Graduate or Professional Degree

14. What was the highest level of education that your mother completed?

Some High School or less High School Graduate Some College/Vocational College Graduate

Graduate or Professional Degree

15. During childhood and adolescence, my father worked mostly:

Full-time plus nights or weekends Full-time Part-time Did not Work

16. During childhood and adolescence, my mother worked mostly:

Full-time plus nights or weekends Full-time Part-time Did not Work

17. What was your family's approximate income when you were a teenager?

Below $\$ 30,000 \quad \$ 30,000-\$ 50,000 \quad \$ 50,000-\$ 100,000 \quad \$ 100,000-\$ 150,000 \quad \$ 150,000$ -

$\$ 250,000$ More than $\$ 250,000$ Don’t know

\section{FATHER}

18. Please place a check on all lines which apply below and fill in the information where there are blank lines (__ f for the father you completed the questionnaire for. Please leave blank all sections that do not apply to you.

\section{Biological Father}

_ Married to mother during childhood and adolescence

_ Died and I lived with my single mother from ages

_ Divorced and I lived with my single mother from ages

_ Divorced and I lived with my single father from ages to

Divorced and I lived with my father and stepmother from ages

Divorced and I lived with my mother and stepfather from ages to

to

If divorced, how often did you see the parent not living with you? (Please specify)

\section{Adoptive Father}

Married to mother during childhood and adolescence

_ Died and I lived with my single mother from ages

_ Divorced and I lived with my single mother from ages

_ Divorced and I lived with my single father from ages to

Divorced and I lived with my father and stepmother from ages

_ Divorced and I lived with my mother and stepfather from ages to to

If divorced, how often did you see the parent not living with you? (Please specify)

\section{Stepfather/Adoptive Stepfather}

I lived with my mother and stepfather from ages

to 
Adopted by my stepfather at age

If divorced, how often did you see the parent not living with you? (Please specify)

Other (Please specify who)

Had a fatherly impact on me from ages to

\section{MOTHER}

19. Please place a check on all lines which apply below and fill in the information where there are blank lines (__ f for the mother you completed the questionnaire for. Please leave blank all sections that do not apply to you.

\section{Biological Mother}

Married to father during childhood and adolescence

_ Died and I lived with my single father from ages

_ Divorced and I lived with my single mother from ages

_ Divorced and I lived with my single father from ages

to

_ Divorced and I lived with my mother and stepfather from ages

_ Divorced and I lived with my father and stepmother from ages to

to

If divorced, how often did you see the parent not living with you? (Please specify)

\section{Adoptive Mother}

Married to father during childhood and adolescence

_ Died and I lived with my single father from ages

_ Divorced and I lived with my single mother from ages

_ Divorced and I lived with my single father from ages

to

Divorced and I lived with my mother and stepfather from ages

_ Divorced and I lived with my father and stepmother from ages

to

to

If divorced, how often did you see the parent not living with you? (Please specify)

\section{Stepmother/ Adoptive Stepmother}

I lived with my father and stepmother from ages to Adopted by my stepmother at age

If divorced, how often did you see the parent not living with you? (Please specify)

$\underline{\text { Other }}$ (Please specify who) Had a motherly impact on me from ages to

FAMILY 
Directions: Finally, please answer the following questions for the family you lived with during most of your childhood and adolescence.

1 Strongly Disagree
2

Disagree
3

Agree
4

Strongly

48. _ We fight a lot in our family.

49. In In our family, family members rarely show anger.

50. In my family, family members often criticize each other.

51. I I often see my parents arguing.

52. _ When my parents have an argument, they say mean things to each other.

53. __ Family members in my family feel very close to each other.

54. Family togetherness is very important in my family.

55. Family members in my family like to spend free time with each other. 
VITA

TARA SHEEHAN

Born, Huntington, New York

1996-2000

B.S., Psychology

B.A., English

State University of New York at Albany

Albany, New York

2002-2006

M.S., Psychology

Florida International University

Miami, Florida

2006-Present

Board Certified Behavior Analyst

Certificant 1-06-3070

2007-2010

Autism Consortium Program Coordinator

Nova Southeastern University

Fort Lauderdale, Florida

2010-2012

Academics Program Coordinator

Nova Southeastern University

Fort Lauderdale, Florida

2012-Present

Research Scientist

Nova Southeastern University

Fort Lauderdale, Florida

\section{PUBLICATIONS AND PRESENTATIONS}

Borgen, J; Cavanaugh, B; Lit, K; Trauschke, S; Benson, J; Shamlian, K, Sheehan, T; \& Mace, F (2013). Response Class Hierarchy Analysis Performed on 20 Clients in an Outpatient Setting. Presented at the Association for Behavior Analysis International, Minneapolis.

Crooks, N.; Sheehan, T.; Russell, J.D.; Safko, D.L. \& Branscum, E. (2007). The Behavior Analyst - Alone Again, Naturally: Forging Alliances in the Community. Panel Discussion at Association for Behavior Analysis, San Diego. 
Cruz, Y \& Sheehan, T (2009). An Exploratory Analysis of the Fidelity of the Applied Behavior Analysis Supervision Handbook. Presented at the Association for Behavior Analysis International, San Antonio.

Kabot, S; Sheehan, T \& O’Brien, H (2008). Starting Right: A Parent-Child, ClassroomBased Intervention Model for 18-36 Month Old Children with ASD. Presented at the Network of Autism Training and Technical Assistance Programs, Columbus.

O’Brien, H; Dietsch, L; Sheehan, T; DeVincentis, M \& Ruf, H (2008). Evaluating the Effectiveness of a Parent Training Procedure Increase Frequency of Eye Contact in Young Children with Autism Spectrum Disorder: Implications for Development of Social Referencing. Presented at the Florida Association for Behavior Analysis, Bonita Springs.

Reeve, C; Cordova, K; Sheehan, T; \& O’Brien, H (2009). A Structured Approach to Ethical Supervision in Applied Behavior Analysis. Presented at the Florida Association for Behavior Analysis, Daytona.

Sheehan, T; Edmonds, S; \& Kabot, S (2012). Strategies for Increasing Engagement in Classroom Activities in Children with Autism and Visual Impairment. Presented at the Florida Association for Behavior Analysis, Jacksonville.

Sheehan, T; Gewirtz, J \& Pelaez, M. (2008). Social Referencing as a Learned Process. Presented at the Association for Behavior Analysis, Chicago.

Sheehan, T; O’Brien, H: Ruf, H: Dietsch, L \& DeVincentis, M. (2008). Training Parents to Evoke and Reinforce Social Referencing Behavior in their Young Child with Autism Spectrum Disorder. Presented at the Association for Behavior Analysis, Chicago.

Sheehan, T. (2006). Training Echoic Rehearsal Strategies Improves Discriminated Responding Controlled Jointly by two Verbal Operants. Presented at the Association for Behavior Analysis, Atlanta.

Sheehan, T.; Ramos-Toca, I.; Mira, S. \& Finley, G. (2006). Parental Nurturance and Child Academic Outcomes: An Exploratory Analysis. Presented at the National Council of Family Relations, Minneapolis.

Sheehan, T (2004). A Comparison of Vygotsky’s Social-Historical Theory of Cognitive Development and Behavior Analysis. Presented at the Association for Behavior Analysis, Boston.

Sheehan, T (2004). The Chomsky/Skinner Debate: Is Grammar a Learned Process? Presented at Association for Behavior Analysis, Boston. 